
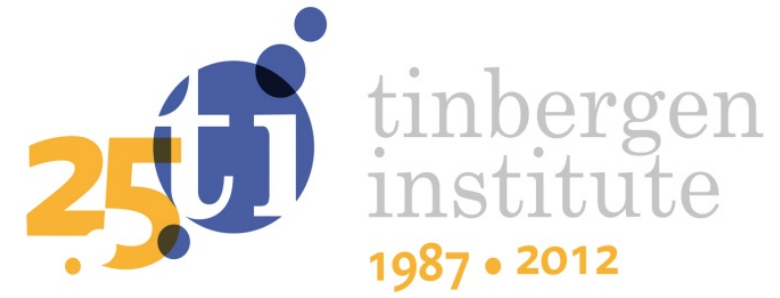

\title{
Fiscal Deficits, Financial Fragility, and the Effectiveness of Government Policies
}

\author{
Markus Kirchner' \\ Sweder van Wijnbergen²
}

' Central Bank of Chile;

2 Faculty of Economics and Business, University of Amsterdam, and Tinbergen Institute. 
Tinbergen Institute is the graduate school and research institute in economics of Erasmus University Rotterdam, the University of Amsterdam and VU University Amsterdam.

More TI discussion papers can be downloaded at http://www.tinbergen.nl

Tinbergen Institute has two locations:

Tinbergen Institute Amsterdam

Gustav Mahlerplein 117

1082 MS Amsterdam

The Netherlands

Tel.: +31(0)205251600

Tinbergen Institute Rotterdam

Burg. Oudlaan 50

3062 PA Rotterdam

The Netherlands

Tel.: +31(0)10 4088900

Fax: $+31(0) 104089031$

Duisenberg school of finance is a collaboration of the Dutch financial sector and universities, with the ambition to support innovative research and offer top quality academic education in core areas of finance.

DSF research papers can be downloaded at: http://www.dsf.nl/

Duisenberg school of finance

Gustav Mahlerplein 117

1082 MS Amsterdam

The Netherlands

Tel.: +31(0)20 5258579 


\title{
Fiscal Deficits, Financial Fragility, and the Effectiveness of Government Policies*
}

\author{
Markus Kirchner ${ }^{\dagger} \quad$ Sweder van Wijnbergen ${ }^{\ddagger}$
}

April 2012

\begin{abstract}
Recent macro developments in the euro area have highlighted the interactions between fiscal policy, sovereign debt, and financial fragility. We take a structural macroeconomic model with frictions in the financial intermediation process, in line with recent research, but introduce asset choice and sovereign debt holdings in the portfolio of banks. Using this model, we emphasize a new crowding-out mechanism that works through reduced private access to credit when banks accumulate sovereign debt under a leverage constraint. Our results show that, when banks invest a substantial fraction of their assets in sovereign debt, the effectiveness of fiscal stimulus policies may be impaired because deficit-financed fiscal expansions may tighten financial conditions to such an extent that private demand is crowded out. We also analyze the macroeconomic effectiveness of liquidity support to commercial banks through recapitalizations or loans by the government and the impact of different ways of financing those policies.
\end{abstract}

Keywords: Financial intermediation; Fiscal policy; Sovereign debt JEL classification: E44; E62; H30

*We thank Pierre Lafourcade, Martin Kliem, Stephane Moyen, and seminar participants at De Nederlandsche Bank, Deutsche Bundesbank, the Central Bank of Chile and the Tinbergen Institute for useful comments. Kirchner acknowledges the hospitality and the financial support of the Economic Research Centre of Deutsche Bundesbank where part of this work was conducted. van Wijnbergen acknowledges financial support of the Gieskes-Strijbis foundation.

${ }^{\dagger}$ Central Bank of Chile; address: Agustinas 1180, Santiago de Chile, Chile; e-mail address: mkirchner@bcentral.cl

$\ddagger$ University of Amsterdam and Tinbergen Institute; address: Valckenierstraat 65-67, 1018 XE Amsterdam, The Netherlands; e-mail address: s.j.g.vanwijnbergen@uva.nl 


\section{Introduction}

Recent macro developments in the euro area have highlighted the interactions of fiscal policy, sovereign debt, and financial fragility. Financial fragility and spiralling sovereign debt were inherited from the global credit crisis that preceded the more recent turmoil in the euro area. Across much of Europe and in the U.S., the fiscal response to the crisis took the form of financial sector support measures and economic stimulus packages that were financed through budgetary deficits. What are the effects of such policies in a situation of financial distress such as emerged after the 2007/2008 credit crisis? Standard macroeconomic models are not set up for policy analysis during crises characterized by financial distress, but new types of models have been developed recently that can be (and have been) used to answer this question; see, in particular, Gertler and Karadi (2011), Gertler and Kiyotaki (2010), and Gertler, Kiyotaki, and Queralto (2012). However, those models assume that government policies are fully funded through markets that are not affected by financial distress and in turn have no direct impact on the financial fragility that the distress situation has led to. For many, if not most countries, this is not a realistic assumption. We show in this paper that relaxing that assumption qualitatively changes the assessment of the effectiveness of deficit-financed government policies as a tool to fight recessions caused by financial distress, and underscores the importance of bank intervention policies to relieve financial distress.

The debt crisis in the euro area has emphasized the importance of the mechanisms and transmission channels we focus on in this paper. On the one hand, commercial banks have to deleverage as a consequence of the weakening of their balance sheets after the earlier credit crisis; but at the same time they are throughout the euro area absorbing increasing amounts of sovereign debt. As a consequence, private access to credit has tightened; even in countries like Germany or the Netherlands credit spreads for corporates have increased while interest rates for sovereigns declined.

We develop a structural macroeconomic model that integrates government deficit financing and financial intermediation with frictions in the intermediation process. These frictions imply a financial accelerator that is able to generate a deep financial crisis following a deterioration of intermediary balance sheets. Furthermore, we incorporate one of the more contentious points of the recent euro area crisis, the potential consequences 
of substantial holdings of sovereign debt by commercial banks for private access to bank credit. We use this model to study the effects of deficit-financed fiscal stimulus policies during such a crisis and also analyze the macroeconomic impact of policies designed to reduce financial distress through direct intervention in commercial bank balance sheets.

Our framework includes financial intermediaries that channel funds or deposits from households (the saving agents) to non-financial firms and the government (the borrowing agents). The intermediation process is subject to a similar agency problem between depositors and intermediaries as in Gertler and Karadi (2011) and Gertler and Kiyotaki (2010). As those studies show, this agency problem leads to endogenous leverage constraints, which in turn gives rise to a powerful financial accelerator mechanism. This accelerator mechanism generates dynamics that broadly reflect the relevant economic dynamics of a financial crisis. However, unlike the models in those studies, our framework allows for different classes of assets in intermediary portfolios instead of only one class, introducing a new crowding-out channel that works through reduced private access to credit when banks accumulate sovereign debt under a leverage constraint.

The specific setup is as follows. The intermediary's asset portfolio consists of government bonds and loans made to non-financial firms. The overall portfolio size is tied to intermediary equity capital through endogenous leverage constraints, but the intermediaries optimize their portfolio composition for any given portfolio size, shifting the composition of their portfolios towards assets with higher expected returns. Through this mechanism, the expected returns on bonds and private claims are jointly determined in equilibrium. Financial frictions and leverage constraints prevent perfect arbitrage, although intermediaries will alter their portfolio composition to exploit rate of return differences. In the general equilibrium, such arbitrage behavior by financial intermediaries leads to co-movements between different credit spreads relative to the rates at which intermediaries obtain funding.

We use this model to highlight the links between government policies and deficit financing in a situation of financial distress. In particular, we analyze the effects of demand (i.e. spending) stimulus and measures targeting the financial sector (i.e. straight transfers to intermediaries, zero interest loans, and loans at penalty rates). This set of policies is sufficient to explain the key implications of the model, but it also suitably captures the main fiscal and bank intervention policy measures that were applied in 
the wake of the global credit crisis. The policies are financed by issuing bonds to intermediaries. We also analyze as a benchmark the case where governments can bypass financial frictions altogether by financing policies through lump-sum taxes levied on household income directly. This is clearly not an option in reality but serves as a benchmark for our results.

Our findings suggest that intermediary financing under leverage constraints has important consequences for the effectiveness of government policies. An early, immediately implemented demand stimulus dampens the recession due to a financial crisis for some time (i.e. it reduces output losses initially), but the dampening impact is much smaller than without the leverage constraints and crowding out through bank portfolio's. And the stimulus tends to prolong the downturn later on as within-period multipliers turn negative already after a few periods. An even more striking result is that a preannounced future stimulus starts out by worsening the recession: in the year leading up to the actual implementation of the stimulus, within-period multipliers are actually negative. Since in the vast majority of budget procedures imply time to implementation, with typical delays of at least a year if not more, this is a highly relevant result. We also find that financial sector policies become less effective under intermediary financing. Some policies such as loans with relatively early repayment can also deepen the downturn. Temporary support can however bring initial stabilization gains if the cost to intermediaries is shifted towards substantially later periods. Overall, these findings raise serious questions about the effectiveness of deficit-financed government policies in situations of financial distress and limited direct capital market access by governments.

Key to our results are the effects of government borrowing on intermediary balance sheet constraints and the associated adverse impacts on the cost of credit to non-financial firms. In our model, a fiscal expansion is associated with an economy-wide increase in credit spreads for the private sector, as higher government deficits tighten intermediary balance sheet constraints. The rise in spreads lowers non-financial sector investment, which can (in some cases more than) offset the output gain of a demand stimulus. The same mechanism also reduces the effectiveness of financial sector policies. The fact that intermediary balance sheet constraints are forward-looking explains the sometimes perverse links between the timing and the effects of government policies that we detect.

This paper is closely related to other studies that emerged out of the experience of 
the credit crisis. $^{1}$ Gertler and Karadi (2011) evaluate the effects of direct government (central bank) credit intermediation, financed by issuing government debt to households, to offset a disruption of private financial intermediation. Gertler and Kiyotaki (2010) consider a generalization of the model in Gertler and Karadi (2011) with an interbank market and also analyze the effects of government equity injections, financed by raising lump-sum taxes from households. But in these studies, government policies are financed directly by households without any financial friction coming in between. Our model allows for deficit financing of fiscal policy through financial intermediaries under leverage constraints, which does more justice to the actual practice of fiscal financing in many developed and most less-developed countries.

In fact, many financial institutions even in developed countries are active in government funding markets. In the euro area, a significant fraction of monetary financial institutions' assets consists of government securities and direct loans to the government: on average equal to about $58 \%$ of the value of loans to non-financial corporations. ${ }^{2}$ In addition, EU banks hold primarily domestic government securities (see ECB, 2010). Using a closed-economy approach, as we do, thus seems sufficient to capture the key elements of sovereign funding structures in Europe, although allowing for cross-border holdings (an extension discussed in a companion paper) allows analysis of the IMF's managing director Christine Lagarde's chains of contagion. Outside of Europe, Japanese bank holdings of government securities as a proportion of total assets have recently gone up to an all-time high, as banks have become the dominant buyers of government bonds. Even in the UK and the U.S., domestic depository institutions' claims on the government still amount to approximately 6\% and 8\% of GDP, respectively (see IMF, 2010), in spite of their much better developed capital markets. Hence, government securities holdings by domestic financial institutions play an important role in most high-income countries, and much more so in most middle-income countries.

Overall, we therefore view this paper as a further step towards a more realistic description of the interactions of sovereign debt and financial fragility, and as one of the first steps to reflect fiscal-financial linkages in macroeconomic models. The recurring

\footnotetext{
${ }^{1}$ Other related studies include, for instance, Bean, Paustian, Penalver, and Taylor (2010), Christiano and Ikeda (2011), and Gertler, Kiyotaki, and Queralto (2012).

${ }^{2}$ Source: European Central Bank (ECB); aggregated balance sheet of euro area monetary financial institutions, March 2011; updated versions are available on the ECB's webpage: http://www.ecb.int/stats/money/aggregates/bsheets.
} 
concerns on the sustainability of government debt in developed countries and the associated spillover effects across financial systems suggest that these are steps into a highly relevant direction.

The remainder of the paper is structured as follows. Section 2 lays out the model. Section 3 discusses the results of model-based simulations. It first compares the effects of deficit-financed and lump-sum-tax-financed changes in government purchases in comparison to a baseline model without financial intermediation to explain the main mechanisms at play. It then analyzes the effects of alternative fiscal policy responses to a simulated crisis to assess the stabilization properties of different policies. Section 4 briefly reviews the related empirical literature to connect the key mechanisms and predictions of the model to the available evidence. Section 5 concludes.

\section{Model description}

We describe a monetary model with sticky prices and financial intermediation that builds on Christiano, Eichenbaum, and Evans (2005) and Gertler and Karadi (2011) but extends the basic structure significantly to enable analysis of commercial banks' role in public deficit financing.

The model has a private sector and a public sector. The private sector consists of a non-financial sector that is formed by households and firms, and a financial sector that is formed by financial intermediaries. The firm production chain is as follows. Capital producers combine used capital purchased from intermediate goods producers with investment goods to produce new productive capital that is again purchased by intermediate goods producers. The latter rent labor services from households, issue claims to financial intermediaries to finance their capital acquisition, and produce differentiated goods that are bought, re-packaged and sold by retail firms in a monopolistically competitive market. Final goods producers buy those goods and combine them into a single output good. The public sector is formed by a monetary authority that sets the risk-free nominal interest rate and a government that conducts purchases of the final good and financial sector policies. The government finances its operations by issuing debt to financial intermediaries or by raising lump-sum taxes from households. The latter option is introduced as a benchmark only, to gauge the impact of the interaction 
between financial frictions and the financing of government expenditure. The intermediaries take funds from depositors that are remunerated at the risk-free nominal interest rate. The problems of the individual agents are discussed in detail in this section.

\subsection{Households}

There is a continuum of infinitely lived households with identical preferences and identical asset endowments. Following Gertler and Karadi (2011), within each household there is a fraction $1-\zeta$ of workers that supply labor to firms and a fraction $\zeta$ of bankers that operate financial intermediaries. There is perfect consumption insurance within the family. Households save by holding deposits at intermediaries that they do not own. Financial intermediaries have finite life times, to exclude the self-financing equilibrium. Thus, at the beginning of each period, with probability $1-\theta$ an individual intermediary exits and with probability $\theta$ the intermediary continues operating. All profits are retained as capital, there are no dividends. If the intermediary exits, the respective bankers become workers and transfer all retained capital back to the household which owns that intermediary. Thus every period $(1-\theta) \zeta$ bankers become workers. To keep the relative proportions fixed, a similar number of workers become bankers. New bankers receive a start-up transfer from their household, as described below.

Household preferences depend on consumption and labor supply, with habit formation in consumption as in Christiano, Eichenbaum, and Evans (2005) to capture consumption dynamics. The objective of a representative household in period $t$ is to maximize expected discounted utility

$$
E_{t} \sum_{s=0}^{\infty} \beta^{s}\left[\log \left(c_{t+s}-v c_{t-1+s}\right)-(1+\varphi)^{-1} h_{t+s}^{1+\varphi}\right], \quad \beta \in(0,1), \quad v \in[0,1), \quad \varphi \geq 0
$$

subject to the period-by-period budget constraint $c_{t}+d_{t}+\tau_{t} \leq w_{t} h_{t}+\left(1+r_{t}^{d}\right) d_{t-1}+\Sigma_{t}$, where $c_{t}$ denotes consumption of final goods, $h_{t}$ denotes hours worked, $w_{t}$ is the hourly wage rate, $d_{t-1}$ are beginning-of-period deposits, $d_{t}$ are end-of-period deposits, $r_{t}^{d}$ is the net real interest rates on deposits, $\tau_{t}$ are lump-sum tax payments, and $\Sigma_{t}$ collects payouts from ownership of both non-financial and financial firms, net of transfers given to household members that enter as bankers at time $t .^{3}$

\footnotetext{
${ }^{3}$ Throughout, real (nominal) variables are denoted by lower (capital) letters, and variables without
} 
The household's decision problem is subject to a no-Ponzi game condition, and the household takes $w_{t}, r_{t}^{d}, \tau_{t}, \Sigma_{t}$, prices, and its initial wealth endowment $d_{-1}$ as given. The first-order conditions corresponding to the solution of the household's problem are

$$
\begin{array}{ll}
c_{t}: & \lambda_{t}=\left(c_{t}-v c_{t-1}\right)^{-1}-\beta v\left(E_{t} c_{t+1}-v c_{t}\right)^{-1}, \\
h_{t}: & h_{t}^{\varphi}=\lambda_{t} w_{t}, \\
d_{t}: & : 1=\beta E_{t} \Lambda_{t, t+1}\left(1+r_{t+1}^{d}\right),
\end{array}
$$

where $\lambda_{t}$ denotes the Lagrangian multiplier associated with the budget constraint and $\Lambda_{t, t+s}=\lambda_{t+s} / \lambda_{t}$ for $s \geq 0$. The budget constraint holds with equality since $\lambda_{t}>0$.

\subsection{Financial intermediaries}

Financial intermediaries are competitive and located on a continuum indexed by $j \in$ $[0,1]$. The intermediaries use the deposits obtained from households to purchase claims issued by intermediate goods firms and also government bonds. Intermediaries thus act as specialists that assist in channeling funds from agents with a surplus of funds to agents with deficits of funds, where the latter include the government. The need for the government to resort to intermediaries is motivated by size arguments: bond issuance typically occurs in large tranches that cannot be handled by small investors.

We model the intermediaries' choice problems as a two-stage process. Each intermediary is operated by a bank manager (or bank board) who makes size decisions and a portfolio manager (or portfolio department) who decides on the structure of assets. In the first stage, the bank manager chooses the total amount of assets relative to deposits to maximize the expected transfer to the household that owns the respective intermediary, as in Gertler and Karadi (2011). Also following the latter, a moral hazard problem constrains the bank manager's ability to obtain external funds. The moral hazard problem gives rise to an endogenous leverage constraint: for given capital, total assets have to be consistent with that leverage constraint if any external funding is to be raised (i.e. the leverage constraint is best interpreted as a capital market participation constraint). In the second stage of the intermediary problem, for a given portfolio size set in the first stage, the portfolio manager chooses portfolio weights. He or she chooses the weights time subscript denote non-stochastic steady state values. 
maximizing the same objective function as the bank manager so the two-stage process is internally consistent.

Total assets of intermediary $j$ at the end of period $t$ are given by

$$
p_{j, t}=q_{t} s_{j, t}^{k}+s_{j, t}^{b},
$$

where $s_{j, t}^{k}$ denote claims on intermediate goods firms by intermediary $j$ that have the relative price $q_{t}$ and that pay a net real return $r_{t+1}^{k}$ at the beginning of period $t+1$, and $s_{j, t}^{b}$ are intermediary $j$ 's government bond holdings that pay a net real return $r_{t+1}^{b}$ at the beginning of period $t+1$. The balance sheet of intermediary $j$ thus looks as follows:

$$
p_{j, t}=d_{j, t}+n_{j, t}
$$

where $d_{j, t}$ denote deposits by households at intermediary $j$ and $n_{j, t}$ denotes the intermediary's net worth. The latter evolves over time as the difference between earnings on assets and interest payments on liabilities minus payments and costs $\Omega$ due to portfolio adjustments:

$$
n_{j, t+1}=\left(1+r_{t+1}^{p}\right) p_{j, t}-\left(1+r_{t+1}^{d}\right) d_{j, t}-\Omega\left(\omega_{j, t}\right) n_{j, t}
$$

where $r_{t+1}^{p}$ is the net real portfolio return. We further define portfolio weights $\omega_{j, t}=$ $q_{t} s_{j, t}^{k} / p_{j, t}$ and $1-\omega_{j, t}=s_{j, t}^{b} / p_{j, t}$, such that the ex-post gross portfolio return satisfies

$$
1+r_{t}^{p}=\left(1+r_{t}^{k}\right) \omega_{j, t-1}+\left(1+r_{t}^{b}\right)\left(1-\omega_{j, t-1}\right)
$$

The term $\Omega\left(\omega_{j, t}\right) n_{j, t}$ above measures convex portfolio adjustment costs that are scaled by the level of net worth. We introduce these costs to achieve stationarity, to be able to use standard local approximation techniques. Such costs could come, for instance, from fees that are incurred when assets are bought and sold on the market. ${ }^{4}$ In the context of our model, those fees are eventually paid out to households. The costs are scaled by the level of net worth to allow for aggregation, as conducted below, motivated by the idea that the total costs that an individual intermediary incurs on portfolio changes should

\footnotetext{
${ }^{4}$ The existence of costly portfolio adjustments is supported by aggregate estimates and micro evidence of infrequent portfolio changes by U.S. stockholders (see Luttmer, 1999; Bonaparte and Cooper, 2009).
} 
depend on the total scale of that intermediary's operations. We apply the following functional form:

$$
\Omega(x)=\frac{\varpi}{2}(x-\bar{\omega})^{2}, \quad \Omega^{\prime}(x)=\varpi(x-\bar{\omega}), \quad \varpi>0, \quad \bar{\omega} \in(0,1) .
$$

The adjustment costs are thus increasing in deviations of the portfolio weight $\omega_{j, t}$ from a long-run target $\bar{\omega}$. The latter pins down the steady state portfolio weights and thus helps to match steady state supply of government bonds and the steady state level of private assets in the general equilibrium, as we show in Appendix A.

\subsubsection{Bank manager}

At the beginning of period $t+1$, after financial payouts have been made, an individual financial intermediary continues operating with probability $\theta$ and exits with probability $1-\theta$, in which case it transfers its retained capital to its household. The bank manager's objective in period $t$ is therefore to maximize the expected value of discounted terminal wealth:

$$
V_{j, t}=E_{t} \sum_{i=0}^{\infty}(1-\theta) \theta^{i} \beta^{i+1} \Lambda_{t, t+1+i} n_{j, t+1+i} .
$$

However, following Gertler and Karadi (2011), we assume that a costly enforcement problem constrains the ability of financial intermediaries to obtain funds from depositors. In particular, at the beginning of period $t$, before financial payouts are made, the bank manager can divert a fraction $\lambda$ of total current assets, $\lambda p_{j, t}$. If that happens, depositors can force the intermediary into bankruptcy to recover the remaining assets, but it is too costly for the depositors to recover the funds that the banker diverted. Of course, in that case the banker will forfeit $V_{j, t}$. Accordingly, for the depositors to be willing to supply funds, the opportunity cost to the banker of diverting assets cannot be smaller than the gain from diverting assets: the incentive constraint $V_{j, t} \geq \lambda p_{j, t}$ must be satisfied.

It is straightforward to show that $V_{j, t}$ can be expressed as follows:

$$
V_{j, t}=v_{t} p_{j, t}-\eta_{t} d_{j, t}-\varrho_{t} n_{j, t}
$$


with

$$
\begin{array}{ll}
v_{t}=\beta E_{t} \Lambda_{t, t+1}\left\{(1-\theta)\left(1+r_{t+1}^{p}\right)+\theta x_{t, t+1} v_{t+1}\right\}, & x_{t, t+1}=p_{j, t+1} / p_{j, t} \\
\eta_{t}=\beta E_{t} \Lambda_{t, t+1}\left\{(1-\theta)\left(1+r_{t+1}^{d}\right)+\theta z_{t, t+1} \eta_{t+1}\right\}, & z_{t, t+1}=d_{j, t+1} / d_{j, t} \\
\varrho_{t}=\beta E_{t} \Lambda_{t, t+1}\left\{(1-\theta) \Omega\left(\omega_{j, t}\right)+\theta f_{t, t+1} \varrho_{t+1}\right\}, & f_{t, t+1}=n_{j, t+1} / n_{j, t}
\end{array}
$$

Holding the other variables constant, the variable $v_{t}$ is the expected discounted marginal gain of an additional unit of assets. The variable $\eta_{t}$ is expected discounted marginal gain cost of another unit of deposits. The variable $\varrho_{t}$ is the expected discounted marginal cost of another unit of net worth conditional on portfolio changes.

We assume that the bank manager takes the expected returns and the portfolio weights as given when deciding on the total size of assets. The Lagrangian of the bank manager's optimization problem is given by $L=V_{j, t}+\mu_{t}\left(V_{j, t}-\lambda p_{j, t}\right)$, where $\mu_{t} \geq 0$ is the Lagrangian multiplier associated with the incentive constraint. The first-order conditions are

$$
\begin{aligned}
p_{j, t} & :\left(1+\mu_{t}\right)\left(v_{t}-\eta_{t}\right)-\mu_{t} \lambda=0 \\
\mu_{t} & : \quad\left(v_{t}-\eta_{t}-\lambda\right) p_{j, t}+\left(\eta_{t}-\varrho_{t}\right) n_{j, t} \geq 0 .
\end{aligned}
$$

The last condition holds with equality if $\mu_{t}>0$, otherwise it holds with strict inequality. The condition for $p_{j, t}$ yields $\mu_{t}=\left[\lambda /\left(v_{t}-\eta_{t}\right)-1\right]^{-1}$. The multiplier is therefore strictly positive if $\lambda>v_{t}-\eta_{t}$. That is, the incentive constraint holds with equality if without the constraint the banker has an incentive to divert funds obtained from depositors and go bankrupt instead of continuing to operate with the additional funds. We assume that the incentive constraint binds within a local region of the non-stochastic steady state and verify that it does bind in the steady state in the calculations in Appendix A.

In the optimum, the total amount of intermediary assets is then tied to intermediary net worth through the leverage constraint $p_{j, t}=\phi_{t} n_{j, t}$, where

$$
\phi_{t}=\frac{\eta_{t}-\varrho_{t}}{\lambda-\left(v_{t}-\eta_{t}\right)}
$$

denotes the intermediary's leverage ratio of assets over net worth. As indicated by (8), 
a higher marginal gain from increasing assets $v_{t}$ supports a higher leverage ratio in the optimum. A higher marginal cost of deposits $\eta_{t}$ lowers the leverage ratio. Higher marginal adjustment costs $\varrho_{t}$ and a larger fraction of divertable funds $\lambda$ also lower the leverage ratio.

\subsubsection{Portfolio manager}

The portfolio manager determines the asset structure of intermediary $j$ 's balance sheet by choosing portfolio weights to maximize the same objective as the bank manager, taking as given the total size of assets $p_{j, t}$ and the returns $r_{t+1}^{i}, i=k, b, d$. Using the portfolio weights, the holdings of individual assets by intermediary $j$ satisfy $q_{t} s_{j, t}^{k}=$ $\omega_{j, t} p_{j, t}$ and $s_{j, t}^{b}=\left(1-\omega_{j, t}\right) p_{j, t}$. The net worth of intermediary $j$ can therefore be rewritten as follows:

$$
\begin{aligned}
n_{j, t+1} & =\left(1+r_{t+1}^{k}\right) q_{t} s_{j, t}^{k}+\left(1+r_{t+1}^{b}\right) s_{j, t}^{b}-\left(1+r_{t+1}^{d}\right) d_{j, t}-\Omega\left(\omega_{j, t}\right) n_{j, t}, \\
& =\left(r_{t+1}^{k}-r_{t+1}^{d}\right) \omega_{j, t} p_{j, t}+\left(r_{t+1}^{b}-r_{t+1}^{d}\right)\left(1-\omega_{j, t}\right) p_{j, t}+\left[1+r_{t+1}^{d}-\Omega\left(\omega_{j, t}\right)\right] n_{j, t} .
\end{aligned}
$$

This expression can be inserted into the objective $V_{j, t}$ from above, to be maximized over $\omega_{j, t}$. The first-order condition looks as follows:

$$
E_{t}\left(r_{t+1}^{k}-r_{t+1}^{d}\right) p_{j, t}=E_{t}\left(r_{t+1}^{b}-r_{t+1}^{d}\right) p_{j, t}+\varpi\left(\omega_{j, t}-\bar{\omega}\right) n_{j, t} .
$$

Dividing through by $n_{j, t}$ and re-writing yields:

$$
E_{t}\left(r_{t+1}^{k}-r_{t+1}^{b}\right) \phi_{t}=\varpi\left(\omega_{j, t}-\bar{\omega}\right)
$$

Accordingly, given the leverage ratio $\phi_{t}$, in the optimum the differential of the expected returns on the individual assets, i.e. $E_{t}\left(r_{t+1}^{k}-r_{t+1}^{b}\right)$, is driven to zero with a speed that is inversely related to the marginal portfolio adjustment costs. Of course, a given leverage ratio limits arbitrage: for given distance from $\bar{\omega}$, a lower leverage ratio (smaller $\phi_{t}$ ) will lead to larger unarbitraged return differences. 


\subsection{Goods-producing firms}

The production side of the economy is characterized by four types of firms that are all owned by the households: (i) a continuum of perfectly competitive intermediate goods firms indexed by $i \in[0,1]$ that produce differentiated goods $y_{i, t}$, (ii) a continuum of monopolistically competitive retail firms indexed by $f \in[0,1]$ that re-package intermediate goods $y_{i, t}$ into retail goods $y_{f, t}$, (iii) a continuum of perfectly competitive final goods producers that combine the intermediate goods into a single good $y_{t}$, and (iv) a continuum of competitive capital goods producers that repair depreciated capital and build new productive capital.

\subsubsection{Final goods producers}

A representative final goods firm combines intermediate goods bought from retailers using the technology $y_{t}^{(\epsilon-1) / \epsilon}=\int_{0}^{1} y_{f, t}^{(\epsilon-1) / \epsilon} d f$, where $\epsilon$ is the elasticity of substitution among intermediate goods. The final goods firm operates in a perfectly competitive market, maximizing profits $P_{t} y_{t}-\int_{0}^{1} P_{f, t} y_{f, t} d f$ over input demands $y_{f, t}$, taking the retail prices $P_{f, t}$ and the final goods price $P_{t}$ as given. The first-order conditions corresponding to the solution of this problem yield input demand functions, $y_{f, t}=\left(P_{f, t} / P_{t}\right)^{-\epsilon} y_{t}$, for all $f$, and an expression for the aggregate price level, $P_{t}^{1-\epsilon}=\int_{0}^{1} P_{f, t}^{1-\epsilon} d f$.

\subsubsection{Retail firms}

Retail firms buy intermediate goods $y_{i, t}$ at the market price $P_{t}^{m}$ and re-package those goods into retail goods $y_{f, t}$ that are sold in a monopolistically competitive market. It takes one unit of intermediate output to make a unit of retail output, i.e. $y_{f, t}=y_{i, t}$. The nominal profit of retailer $f$ in period $t$ is thus given by $\left(P_{f, t}-P_{t}^{m}\right) y_{f, t}$. Following Calvo (1983) and Yun (1996), in each period a fraction $1-\psi$ of firms can optimally reset their prices, where $\psi$ is exogenously given. A firm that can optimally reset its price maximizes the expected sum of discounted profits. The stochastic discount factor for nominal payouts to households is given by $\beta^{s} \Lambda_{t, t+s}\left(P_{t} / P_{t+s}\right)$, for $s \geq 0$. The relevant part of firm $f$ 's optimization problem is then as follows:

$$
\max _{P_{f, t}} E_{t} \sum_{s=0}^{\infty}(\beta \psi)^{s} \Lambda_{t, t+s}\left(P_{t} / P_{t+s}\right)\left[P_{f, t}-P_{t+s}^{m}\right] y_{f, t+s},
$$


subject to the demand function $y_{f, t}=\left(P_{f, t} / P_{t}\right)^{-\epsilon} y_{t}$. By symmetry, all optimizing firms will set the same price $P_{t}^{*}$. Defining the relative price $m_{t}=P_{t}^{m} / P_{t}$, the first-order condition is given by

$$
\frac{P_{t}^{*}}{P_{t}}=\frac{\epsilon}{\epsilon-1} \frac{E_{t} \sum_{s=0}^{\infty}(\beta \psi)^{s} \lambda_{t+s} P_{t+s}^{\epsilon} P_{t}^{-\epsilon} m_{t+s} y_{t+s}}{E_{t} \sum_{s=0}^{\infty}(\beta \psi)^{s} \lambda_{t+s} P_{t+s}^{\epsilon-1} P_{t}^{1-\epsilon} y_{t+s}} .
$$

Defining further the relative price $\pi_{t}^{*}=P_{t}^{*} / P_{t}$ and the gross inflation rate $\pi_{t}=P_{t} / P_{t-1}$, the first-order condition can be re-written in recursive form as follows:

$$
\pi_{t}^{*}=\frac{\epsilon}{\epsilon-1} \frac{\Xi_{1, t}}{\Xi_{2, t}}, \quad \Xi_{1, t}=\lambda_{t} m_{t} y_{t}+\beta \psi E_{t} \pi_{t+1}^{\epsilon} \Xi_{1, t+1}, \quad \Xi_{2, t}=\lambda_{t} y_{t}+\beta \psi E_{t} \pi_{t+1}^{\epsilon-1} \Xi_{2, t+1} .
$$

Finally, by Calvo pricing, the aggregate price level evolves as follows (see Yun, 1996):

$$
1=(1-\psi)\left(\pi_{t}^{*}\right)^{1-\epsilon}+\psi \pi_{t}^{\epsilon-1}
$$

\subsubsection{Intermediate goods producers}

Intermediate goods firms produce differentiated goods that are sold in a perfectly competitive market. Each firm $i$ has access to the following production technology:

$$
y_{i, t}=a_{t}\left(\xi_{t} k_{i, t-1}\right)^{\alpha} h_{i, t}^{1-\alpha}, \quad \log x_{t}=\rho_{x} \log x_{t-1}+\varepsilon_{x, t}, \quad \rho_{x} \in[0,1),
$$

for $x=a, \xi$ and with $\varepsilon_{x, t} \sim N\left(0, \sigma_{x}^{2}\right)$. Here, $a_{t}$ denotes total factor productivity and $\xi_{t}$ denotes the quality of capital. Thus, $\xi_{t} k_{i, t-1}$ measures the effective quantity of capital usable for production in period $t$. The shock $\xi_{t}$ is meant to capture economic depreciation or obsolescence of capital and provides a simple source of variation in the quality of capital and thus the value of intermediary assets in the general equilibrium (see Gertler and Karadi, 2011). Each period, firm $i$ rents labor services $h_{i, t}$ at the wage rate $w_{t}$ from households and finances its capital acquisition by obtaining funds from financial intermediaries. The timing is as follows. At the end of period $t$, the firm acquires capital $k_{i, t}$ for use in production in period $t+1$. To finance the capital acquisition, the firm issues claims $s_{i, t}^{k}$ to intermediaries equal to the units of capital acquired, which pay a state-contingent net real return $r_{t+1}^{k}$ at the beginning of period $t+1$. The price of each claim is the relative price of a unit of capital $q_{t}$. After production in pe- 
riod $t+1$, the firm sells the effective capital that has depreciated during that period, $(1-\delta) \xi_{t+1} k_{i, t}$, at the price $q_{t+1}$. Thus, firm $i$ 's real profits in period $t$ are given by $\Pi_{i, t}=m_{t} a_{t}\left(\xi_{t} k_{i, t-1}\right)^{\alpha} h_{i, t}^{1-\alpha}+q_{t}(1-\delta) \xi_{t} k_{i, t-1}-\left(1+r_{t}^{k}\right) q_{t-1} k_{i, t-1}-w_{t} h_{i, t}$. Taking the relative output price $m_{t}$ and the input prices $q_{t}, r_{t}^{k}$, and $w_{t}$ as given, intermediate goods firms maximize $E_{t} \sum_{s=0}^{\infty} \beta^{s} \Lambda_{t, t+s} \Pi_{i, t+s}$. The first-order conditions are as follows:

$$
\begin{aligned}
h_{i, t}: & w_{t}=(1-\alpha) m_{t} y_{i, t} / h_{i, t}, \\
k_{i, t} & : \quad E_{t} \beta \Lambda_{t, t+1} q_{t}\left(1+r_{t+1}^{k}\right)=E_{t} \beta \Lambda_{t, t+1}\left[\alpha m_{t+1} y_{i, t+1} / k_{i, t}+q_{t+1}(1-\delta) \xi_{t+1}\right] .
\end{aligned}
$$

Perfect competition implies that each intermediate goods firm earns zero profits period by period. Accordingly, the firms pay out the ex-post return on capital to the financial intermediaries, which can be obtained by substituting out $w_{t}$ in the zero profit condition, i.e. $\Pi_{i, t}=0$ :

$$
r_{t}^{k}=q_{t-1}^{-1}\left[\alpha m_{t} y_{i, t} / k_{i, t-1}+q_{t}(1-\delta) \xi_{t}\right]-1
$$

Solving the last expression and the first-order condition for $h_{i, t}$ for the factor demands yields

$$
h_{i, t}=(1-\alpha) m_{t} w_{t}^{-1} y_{i, t}, \quad k_{i, t-1}=\alpha m_{t}\left[q_{t-1}\left(1+r_{t}^{k}\right)-q_{t}(1-\delta) \xi_{t}\right]^{-1} y_{i, t} .
$$

Inserting the factor demands into the technology constraint then yields the following expression for the relative intermediate output price:

$$
m_{t}=\alpha^{-\alpha}(1-\alpha)^{\alpha-1} a_{t}^{-1}\left\{w_{t}^{1-\alpha}\left[q_{t-1}\left(1+r_{t}^{k}\right) \xi_{t}^{-1}-q_{t}(1-\delta)\right]^{\alpha}\right\}
$$

\subsection{Capital-producing firms}

After production in period $t$, competitive capital producers purchase the stock of depreciated capital, given by $(1-\delta) \xi_{t} k_{t-1}$, from the intermediate goods firms at the relative price $q_{t}$. The capital producers combine the depreciated capital with investment goods to produce new productive capital, using an identical capital accumulation technology. The newly produced capital is then sold back to the intermediate goods firms and any profits are transferred to the households. A representative capital producer's accumu- 
lation technology is given by

$$
k_{t}=(1-\delta) \xi_{t} k_{t-1}+\left[1-\Psi\left(\iota_{t}\right)\right] i_{t}, \quad \Psi\left(\iota_{t}\right)=\frac{\gamma}{2}\left(\iota_{t}-1\right)^{2}, \quad \gamma \geq 0, \quad \delta \in[0,1]
$$

where $i_{t}$ denotes investment expenditures in terms of the final good as a materials input, with relative price unity, and $\Psi(\cdot)$ are convex investment adjustment costs in $\iota_{t}=i_{t} / i_{t-1}$. The capitalproducer's real profits in period $t$ are then around a fixed trend given by $q_{t} k_{t}-q_{t}(1-\delta) \xi_{t} k_{t-1}-i_{t}$. The problem of the capital producer is then to solve

$$
\max _{i_{t}} E_{t} \sum_{s=0}^{\infty} \beta^{s} \Lambda_{t, t+s}\left\{q_{t+s}\left[1-\Psi\left(\iota_{t+s}\right)\right]-1\right\} i_{t+s}
$$

taking $q_{t}$ as given. The first-order condition is as follows:

$$
q_{t}\left[1-\Psi\left(\iota_{t}\right)\right]-1-q_{t} \iota_{t} \Psi^{\prime}\left(\iota_{t}\right)+\beta E_{t} \Lambda_{t, t+1} q_{t+1} \iota_{t+1} \Psi^{\prime}\left(\iota_{t+1}\right)=0,
$$

where $\Psi^{\prime}\left(\iota_{t+s}\right)$ denotes the partial derivative of $\Psi(\cdot)$ with respect to $\iota_{t+s}$ for $s \geq 0$. Substituting out the functional terms, the price of capital is seen to satisfy

$$
\frac{1}{q_{t}}=1-\frac{\gamma}{2}\left(\frac{i_{t}}{i_{t-1}}-1\right)^{2}-\frac{\gamma i_{t}}{i_{t-1}}\left(\frac{i_{t}}{i_{t-1}}-1\right)+\beta E_{t} \Lambda_{t, t+1} \frac{q_{t+1}}{q_{t}}\left(\frac{i_{t+1}}{i_{t}}\right)^{2} \gamma\left(\frac{i_{t+1}}{i_{t}}-1\right) .
$$

\subsection{Fiscal policy}

The government conducts purchases of the final good and financial sector policies. Government purchases $g_{t}$ consist of a stochastic part $\tilde{g}_{t}$ plus a possible response to shocks to the capital quality $\xi_{t}$ :

$$
g_{t}=\tilde{g}_{t}+\varsigma\left(\xi_{t-l}-\xi\right), \quad \varsigma \leq 0, \quad l \geq 0
$$

where $\tilde{g}_{t}$ follows an autoregressive process in logs around $\bar{g}$. We introduce concurrent shocks that come as a surprise, $\varepsilon_{g, t}^{u}$, and shocks that are pre-announced four periods ahead of time, $\varepsilon_{g, t-4}^{a}$, which results in the following process for government expenditure: $\log \left(\tilde{g}_{t} / \bar{g}\right)=\rho_{g} \log \left(\tilde{g}_{t-1} / \bar{g}\right)+\varepsilon_{g, t}^{u}+\varepsilon_{g, t-4}^{a}$, with $\varepsilon_{g, t}^{x} \sim N\left(0, \sigma_{g, x}^{2}\right)$ for $x=u, a, \rho_{g} \in[0,1)$, and $\bar{g}>0$. The parameter $\varsigma$ determines the spending response to shocks to the quality of capital. Below, this shock serves as the initiating disturbance leading to a financial 
crisis. If $\varsigma<0$, spending increases during the crisis above its steady state value. If $\varsigma=0$, there is no government intervention. Through the parameter $l$, the response occurs contemporaneously $(l=0)$ or with some lag $(l>0)$. Although it may seem less appealing from a practical point of view than, for instance, an endogenous output feedback, an exogenous feedback of this type makes the policy experiments conducted below comparable by excluding second-round effects of induced output changes back into more government interventions.

We also allow for different kinds of government interventions in the financial sector. In particular, we assume that the government is willing to provide funds $n_{g, t}$ to financial intermediaries according to a rule that is symmetric to the spending rule:

$$
n_{g, t}=\varkappa\left(\xi_{t-l}-\xi\right), \quad \varkappa \leq 0, \quad l \geq 0
$$

According to this rule, if $\varkappa<0$, the government provides funds in the face of shocks to the quality of capital, which can again occur contemporaneously or with some lag as determined by $l$. If $\varkappa=0$, there are no government interventions in the financial sector. In addition, we allow for the possibility that the funds provided in this way are repaid by the intermediaries, where the period- $t$ repayment $\tilde{n}_{g, t}$ is specified as follows:

$$
\tilde{n}_{g, t}=\vartheta n_{g, t-e}, \quad \vartheta \geq 0, \quad e \geq 1 .
$$

Hence, the size of intermediary repayments relative to the funds provided by the government is determined by the penalty factor $\vartheta$ : if $\vartheta=0$, the government makes a transfer or "gift" to intermediaries, $\vartheta=1$ nests the case of a zero-interest loan, and if $\vartheta>1$, the funds need to be repaid at some positive (penalty) interest rate. Furthermore, any repayments occur with some delay as determined by the parameter $e^{5,6}$

Let $b_{t-1}\left(b_{t}\right)$ denote the stock of government debt at the beginning (at the end) of period $t$. We also make the assumption that the government can raise lump-sum taxes from households as an alternative to raising funds through the banking sector. This

\footnotetext{
${ }^{5}$ The provision of funds through $n_{g, t}-\tilde{n}_{g, t}$ is similar to an equity injection by the government into the intermediary sector; see equation (18) in Section 2.7.

${ }^{6}$ Similar types of policies have been implemented during the global credit crisis. For example, in the Netherlands penalty interest rates up to 50 percent were charged on government loans to financial institutions that were to be repaid after about three years.
} 
assumption is only introduced to provide a benchmark case where the government can bypass financial fragility problems; this allows us to clearly show the impact of financial fragility and intermediary deficit financing. The taxes follow the rule

$$
\tau_{t}=\bar{\tau}+\kappa_{b}\left(b_{t-1}-b\right)+\kappa_{g}\left(g_{t}-g\right)+\kappa_{n} n_{g, t}, \quad \kappa_{b}>0, \quad \kappa_{g}, \kappa_{n} \in[0,1], \quad \bar{\tau}>0 .
$$

With $\kappa_{b}>0$, this tax rule ensures fiscal solvency for any finite initial level of debt Bohn (1998). The benchmark case that allows us to judge the effects of intermediary deficit financing is introduced through the other two terms in the tax rule, with the parameters $\kappa_{g}$ and $\kappa_{n}$. For $\kappa_{g}=0\left(\kappa_{n}=0\right)$, goods purchases (financial sector policies) are fully financed by deficits. For $\kappa_{g}=1$ and $\kappa_{n}=1$, fiscal policy is entirely financed by lump-sum taxes on households. The introduction of small distortionary taxes for debt repayment is unlikely to change our main qualitative conclusions.

The period-by-period government budget constraint is then given by

$$
b_{t}+\tau_{t}+\tilde{n}_{g, t}=g_{t}+n_{g, t}+\left(1+r_{t}^{b}\right) b_{t-1} .
$$

\subsection{Monetary policy}

To close the model, we assume that the monetary authority sets the risk-free nominal interest rate on deposits $r_{t}^{n}$ to stabilize inflation and output according to a Taylor rule of the form

$$
r_{t}^{n}=\left(1-\rho_{r}\right)\left[r^{n}+\kappa_{\pi}\left(\pi_{t}-\bar{\pi}\right)+\kappa_{y} \log \left(y_{t} / y_{t-1}\right)\right]+\rho_{r} r_{t-1}^{n}+\varepsilon_{r, t}, \quad \kappa_{y} \geq 0, \quad \kappa_{\pi}>1,
$$

with $\rho_{r} \in[0,1)$ and $\varepsilon_{r, t} \sim N\left(0, \sigma_{r}^{2}\right)$. The parameter $\bar{\pi} \geq 1$ stands for the inflation target. The strength of the monetary authority's reaction to fluctuations of inflation and output is determined by the parameters $\kappa_{\pi}$ and $\kappa_{y}$, where we have imposed the Taylor principle as $\kappa_{\pi}>1$ (Taylor, 1993). We also allow for an interest rate smoothing component in the Taylor rule, where the strength of interest rate smoothing is controlled by the parameter $\rho_{r} \cdot{ }^{7}$ The following Fisher relation then defines the ex-post gross real interest rate on

\footnotetext{
${ }^{7}$ The specification of the Taylor rule uses the log deviation of current output from last period's output, to approximate the output gap that appears in the original version of Taylor (1993), following common specifications in empirical macroeconomic models (e.g. Christoffel, Coenen, and Warne, 2008).
} 
deposits:

$$
1+r_{t}^{d}=\left(1+r_{t-1}^{n}\right) \pi_{t}^{-1}
$$

Notice that the model emphasizes the direct links of e.g. central bank lending rates to intermediary funding rates by the choice of the deposit rate as the instrument for monetary policy. The interest rate on government bonds is however endogenously determined in the general equilibrium.

\subsection{Aggregation and market clearing}

\subsubsection{Financial variables}

Given the overall asset size, $p_{j, t}=\phi_{t} n_{j, t}$, and the asset structure of the balance sheets of individual financial intermediaries, $q_{t} s_{j, t}^{k}=\omega_{j, t} \phi_{t} n_{j, t}$ and $s_{j, t}^{b}=\left(1-\omega_{j, t}\right) \phi_{t} n_{j, t}$, the evolution of intermediary $j$ 's net worth can be re-written as follows:

$$
n_{j, t+1}=\left[\left(r_{t+1}^{p}-r_{t+1}^{d}\right) \phi_{t}+1+r_{t+1}^{d}-\Omega\left(\omega_{j, t}\right)\right] n_{j, t},
$$

which leads to the following expressions for growth rates of the various balance sheet components:

$$
\begin{aligned}
& f_{t, t+1}=n_{j, t+1} / n_{j, t}=\left(r_{t+1}^{p}-r_{t+1}^{d}\right) \phi_{t}+1+r_{t+1}^{d}-\Omega\left(\omega_{j, t}\right), \\
& x_{t, t+1}=p_{j, t+1} / p_{j, t}=\left(\phi_{t+1} / \phi_{t}\right)\left(n_{j, t+1} / n_{j, t}\right)=\left(\phi_{t+1} / \phi_{t}\right) f_{t, t+1}, \\
& z_{t, t+1}=d_{j, t+1} / d_{j, t}=\left(\phi_{t+1}-1\right) /\left(\phi_{t}-1\right)\left(n_{j, t+1} / n_{j, t}\right)=\left(\phi_{t+1}-1\right) /\left(\phi_{t}-1\right) f_{t, t+1},
\end{aligned}
$$

The portfolio problem of intermediary $j$ further implies that the individual portfolio weights are given by $\omega_{j, t}=\varpi^{-1} E_{t}\left(r_{t+1}^{k}-r_{t+1}^{b}\right) \phi_{t}+\bar{\omega}$. Substituting out the latter as well as $v_{t}, \eta_{t}$, and $\varrho_{t}$ in the above terms, it follows that none of the components of $\phi_{t}$ depend on individual factors. Thus, we also have that $\omega_{j, t}=\omega_{t}$ for all $j$.

The aggregate asset demands $s_{t}^{k}=\int_{0}^{1} s_{j, t}^{k} d j$ and $s_{t}^{b}=\int_{0}^{1} s_{j, t}^{b} d j$ then follow as

$$
q_{t} s_{t}^{k}=\omega_{t} \phi_{t} n_{t}, \quad s_{t}^{b}=\left(1-\omega_{t}\right) \phi_{t} n_{t}
$$

where $n_{t}=\int_{0}^{1} n_{j, t}$ denotes aggregate net worth. Aggregate net worth $n_{t}$ is the sum of 
total net worth of financial intermediaries that continue operating $n_{c, t}$, total net worth of newly entering intermediaries $n_{e, t}$, and net transfers by the government, $n_{g, t}-\tilde{n}_{g, t}$. Total net worth of continuing intermediaries is given by $n_{c, t}=\theta\left[\left(r_{t}^{p}-r_{t}^{d}\right) \phi_{t-1}+1+r_{t}^{d}-\right.$ $\left.\Omega\left(\omega_{t-1}\right)\right] n_{t-1}$. To obtain an expression for $n_{e, t}$, it is assumed that new bankers receive a start-up transfer from households equal to a fraction $\chi /(1-\theta)$ of aggregate net worth at the end of period $t-1,(1-\theta) n_{t-1}$. Thus, $n_{e, t}=(\chi /(1-\theta)) *(1-\theta) n_{t-1}=\chi n_{t-1}$. Accordingly, we have

$$
n_{t}=\left\{\theta\left[\left(r_{t}^{p}-r_{t}^{d}\right) \phi_{t-1}+1+r_{t}^{d}-(\varpi / 2)\left(\omega_{t-1}-\bar{\omega}\right)^{2}\right]+\chi\right\} n_{t-1}+n_{g, t}-\tilde{n}_{g, t},
$$

Further, aggregate securities issued by intermediate goods firms to financial intermediaries satisfy $q_{t} \int_{0}^{1} s_{i, t}^{k} d i=q_{t} \int_{0}^{1} s_{j, t}^{k} d j=q_{t} \int_{0}^{1} k_{i, t} d i$, or, using the market clearing conditions $s_{t}^{k}=\int_{0}^{1} s_{i, t}^{k} d i=\int_{0}^{1} s_{j, t}^{k} d j$ and $k_{t}=\int_{0}^{1} k_{i, t} d i$ :

$$
s_{t}^{k}=k_{t} .
$$

Similarly, aggregate bonds issued by the government to financial intermediaries satisfy

$$
s_{t}^{b}=b_{t}
$$

The aggregate asset portfolio follows by integrating over individual portfolios:

$$
p_{t}=\int_{0}^{1} p_{j, t} d j=q_{t} \int_{0}^{1} s_{j, t}^{k} d j+\int_{0}^{1} s_{j, t}^{b} d j=q_{t} s_{t}^{k}+s_{t}^{b} .
$$

Aggregate deposits follow by integrating over individual balance sheets:

$$
d_{t}=\int_{0}^{1} d_{j, t} d j=\int_{0}^{1} p_{j, t} d j-\int_{0}^{1} n_{j, t} d j=p_{t}-n_{t}
$$

\subsubsection{Factor demands}

Demand by final goods producers for each retail good is $y_{f, t}=y_{i, t}=y_{t}\left(P_{f, t} / P_{t}\right)^{-\epsilon}$, for all $f$ and all $i$. With $y_{i, t}=y_{f, t}$, the factor demands by firm $i$ are given by

$$
h_{i, t}=(1-\alpha) m_{t} w_{t}^{-1} y_{f, t}, \quad k_{i, t-1}=\alpha m_{t}\left[q_{t-1}\left(1+r_{t}^{k}\right)-q_{t}(1-\delta) \xi_{t}\right]^{-1} y_{f, t} .
$$


The aggregate factor demands follow from the market clearing conditions $\int_{0}^{1} h_{i, t} d i=h_{t}$ and $\int_{0}^{1} k_{i, t-1} d i=k_{t-1}$ :

$$
h_{t}=(1-\alpha) m_{t} w_{t}^{-1} y_{t} \Delta_{t}, \quad k_{t-1}=\alpha m_{t}\left[q_{t-1}\left(1+r_{t}^{k}\right)-q_{t}(1-\delta) \xi_{t}\right]^{-1} y_{t} \Delta_{t},
$$

where $\Delta_{t}=\int_{0}^{1}\left(P_{f, t} / P_{t}\right)^{-\epsilon} d f$ is a price dispersion term with the recursive form

$$
\Delta_{t}=(1-\psi)\left(\pi_{t}^{*}\right)^{-\epsilon}+\psi \pi_{t}^{\epsilon} \Delta_{t-1}
$$

see Yun (1996). Hence, the aggregate capital-labor ratio follows as

$$
k_{t-1} / h_{t}=\alpha(1-\alpha)^{-1} w_{t}\left[q_{t-1}\left(1+r_{t}^{k}\right)-q_{t}(1-\delta) \xi_{t}\right]^{-1}=k_{i, t-1} / h_{i, t}
$$

\subsubsection{Aggregate supply}

Integrating $y_{i, t}=a_{t}\left(\xi_{t} k_{i, t-1}\right)^{\alpha} h_{i, t}^{1-\alpha}$ over $i$, it follows that

$$
\int_{0}^{1} a_{t}\left(\xi_{t} k_{i, t-1}\right)^{\alpha} h_{i, t}^{1-\alpha} d i=a_{t} \xi_{t}^{\alpha}\left(\frac{k_{t-1}}{h_{t}}\right)^{\alpha} \int_{0}^{1} h_{i, t} d i=a_{t}\left(\xi_{t} k_{t-1}\right)^{\alpha} h_{t}^{1-\alpha}
$$

Integrating $y_{f, t}=y_{t}\left(P_{f, t} / P_{t}\right)^{-\epsilon}$ over $f$ thenm yields output of the final good:

$$
y_{t} \Delta_{t}=a_{t}\left(\xi_{t} k_{t-1}\right)^{\alpha} h_{t}^{1-\alpha}
$$

\subsubsection{Goods market clearing}

Goods market clearing further requires that aggregate demand equals aggregate supply:

$$
c_{t}+i_{t}+g_{t}=y_{t}
$$

\subsection{Equilibrium}

The rational expectations equilibrium of this model is then the set of sequences $\left\{c_{t}, h_{t}, w_{t}\right.$, $\left.i_{t}, k_{t}, q_{t}, y_{t}, m_{t}, \pi_{t}, \pi_{t}^{*}, \Xi_{1, t}, \Xi_{2, t}, \Delta_{t}, r_{t}^{d}, r_{t}^{p}, r_{t}^{k}, r_{t}^{b}, \omega_{t}, v_{t}, \eta_{t}, \varrho_{t}, \phi_{t}, n_{t}, s_{t}^{k}, s_{t}^{b}, p_{t}, d_{t}, b_{t}\right\}_{t=0}^{\infty} \quad$ and shadow prices $\left\{\lambda_{t}\right\}_{t=0}^{\infty}$, such that for given initial prices and initial values, a fiscal policy $\left\{g_{t}, n_{g, t}, \tilde{n}_{g, t}, \tau_{t}\right\}_{t=0}^{\infty}$, a monetary policy $\left\{r_{t}^{n}\right\}_{t=0}^{\infty}$, and sequences of shocks $\left\{a_{t}, \xi_{t}\right\}_{t=0}^{\infty}$, conditions (1)-(26), dropping the $j$ subscripts for individual intermediaries where ap- 
propriate, and the transversality conditions are satisfied. This closes the description of the model. The model is solved by a first-order perturbation around the non-stochastic steady state which is derived in Appendix A.

\section{Model analysis}

\subsection{Calibration}

Table 1 lists the choice of parameters for the baseline version of the model. For comparability with the existing academic literature we have chosen parameters that are commonly used in similar DSGE models. ${ }^{8}$ In particular, the calibration follows Gertler and Karadi (2011). This concerns the subjective discount factor $\beta$, the degree of habit formation $\nu$, the inverse Frisch elasticity of labor supply $\varphi$, the elasticity of substitution among intermediate goods $\epsilon$, the Calvo probability of keeping prices fixed $\psi$, the effective capital share in production $\alpha$, and the investment adjustment cost parameter $\gamma$. The parameters in the monetary policy rule are set to conventional values.

In addition, we take a conservative stance on the parameters that are specific to our model: we use a small value for the portfolio adjustment cost parameter $\varpi$ to limit the impact of the adjustment costs on the dynamics to a minimum (cf. Footnote 11 below). The value of the debt feedback on taxes $\kappa_{b}$ is chosen to have stability conditions satisfied in both the version of the model with financial frictions and the version without financial frictions and financial intermediaries (see Appendix B).

Following again Gertler and Karadi (2011), the steady state leverage ratio $\phi$ is set to four to roughly match aggregate U.S. financial data. The steady state credit spread $\Gamma$ is set to one hundred basis points to match the pre-2007 spreads of bank lending rates to risk-free bonds. The average survival rate of bankers $\Theta=1 /(1-\theta)$ is set to sixteen quarters (thus smaller than in Gertler and Karadi, 2011) by calibrating the survival probability $\theta$, to make sure that the proportional transfer to entering bankers $\chi$ is positive (see Appendix A). To roughly match U.S. macroeconomic data, the steady

\footnotetext{
${ }^{8} \mathrm{~A}$ large fraction of those parameters is based on attempts to match moments of U.S. data. We do not want to imply that the mechanisms we discuss are particularly relevant to the U.S., given the relatively small role banks play in U.S. debt markets. But the interaction between bank balance sheets and sovereign debt has been at the core of the euro area crisis and is also relevant in most emerging markets.
} 
Table 1: Model parameters

\begin{tabular}{lll}
\hline Parameter & Value & Definition \\
\hline $\begin{array}{l}\text { Households } \\
\beta\end{array}$ & 0.990 & $\begin{array}{l}\text { Subjective discount factor } \\
\nu\end{array}$ \\
$\varphi$ & 0.815 & $\begin{array}{l}\text { Degree of habit formation } \\
\text { Inverse Frisch elasticity of labor supply }\end{array}$ \\
\hline Financial intermediaries & 0.276 & \\
$\lambda$ & 0.226 & Fraction of assets that can be diverted \\
$\theta$ & 0.938 & Survival probability of bankers \\
$\chi$ & 0.016 & Proportional transfer to entering bankers \\
$\varpi$ & 0.001 & Portfolio adjustment cost parameter \\
\hline Goods-producing firms & & \\
$\epsilon$ & 4.176 & Elasticity of substitution \\
$\psi$ & 0.779 & Calvo probability of keeping prices fixed \\
$\alpha$ & 0.330 & Share of effective capital in production \\
\hline Capital-producing firms & & \\
$\delta$ & 0.079 & Depreciation rate of effective capital \\
$\gamma$ & 1.728 & Investment adjustment cost parameter \\
\hline Policy & & \\
$\kappa_{b}$ & 0.020 & Government debt feedback on taxes \\
$\rho_{r}$ & 0.800 & Interest rate smoothing parameter \\
$\kappa_{\pi}$ & 1.500 & Inflation feedback on nominal interest rate \\
$\kappa_{y}$ & 0.125 & Output feedback on nominal interest rate \\
\hline
\end{tabular}

state ratios of investment and government spending over GDP $i / y$ and $g / y$ are set to 20 percent, the latter by calibrating $\delta$, and the ratio $b / y$ is set to 2.4 , which implies an annual debt-to-GDP ratio of 60 percent.

\subsection{Effects of a surprise spending shock}

We first examine the dynamics of the response to a surprise spending shock. Figure 1 shows the responses of selected variables to an unanticipated increase in government spending (goods purchases) that is normalized to $1 \%$ of GDP on impact and that is persistent with autocorrelation coefficient $\rho_{g}=0.8$. We consider the case of full intermediary financing of the deficit, and, as a benchmark, the case of full household financing through lump-sum taxes. ${ }^{9}$ The figure also shows the impulse responses from a version

\footnotetext{
${ }^{9}$ This variant is observationally equivalent to one where financial intermediaries would take deposits from households but face no leverage constraints on their financing of public debt, like in
} 

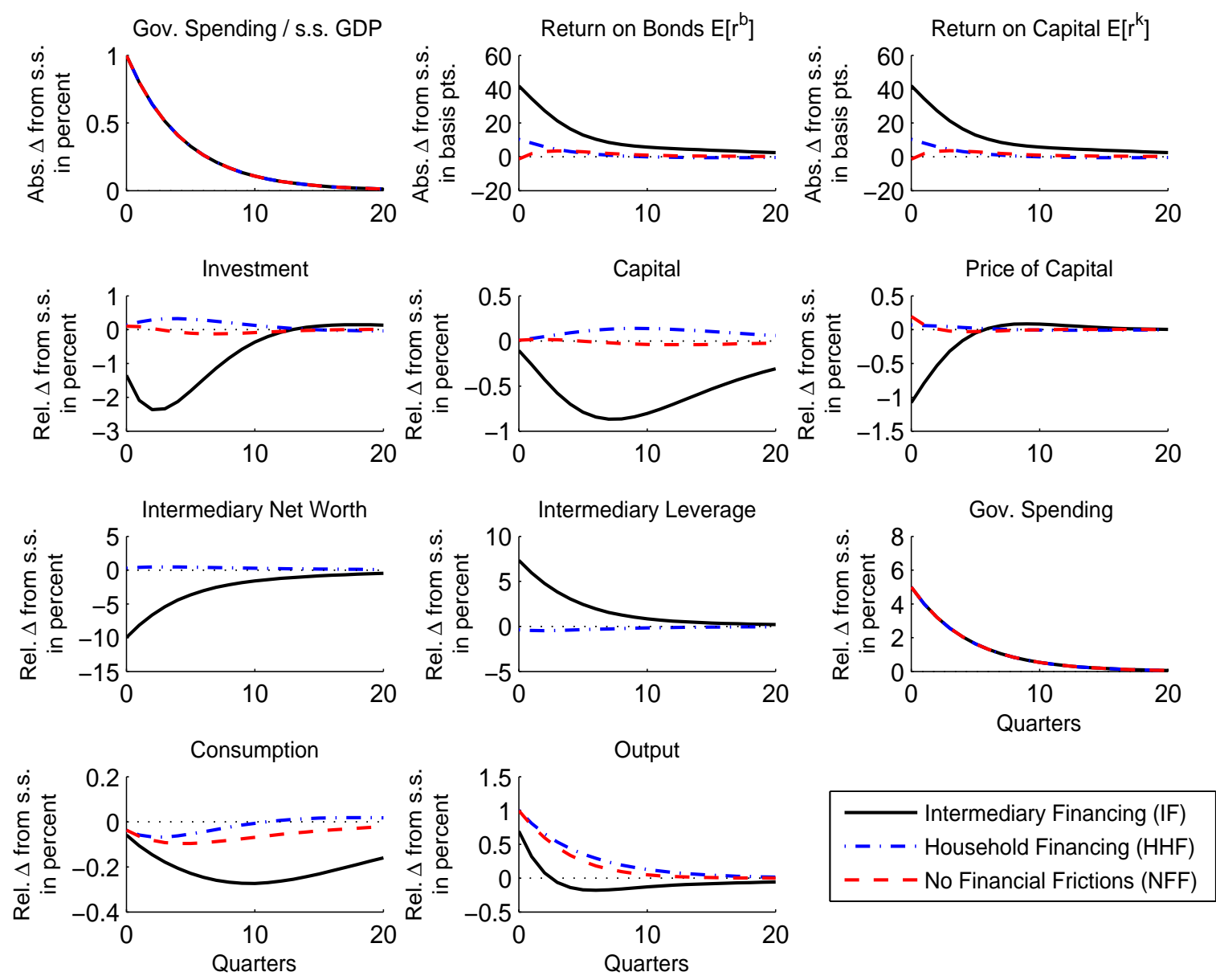

Figure 1: Impulse responses to a surprise spending shock. Note. Unexpected increase in government spending in quarter 0 (innovation $\varepsilon_{g, t}^{u}$ ) by $1 \%$ of GDP relative to steady state.

of the model without financial intermediaries at all, eliminating financial frictions altogether, as another reference case. ${ }^{10}$ This version of the model is described in Appendix B. Comparing the Intermediary Financing (IF) case with Household Financing (HHF) shows the impact of placing debt at already financially distressed banks; comparison with the No Financial Frictions (NFF) case shows the impact of financial fragility per se, since there are no leverage constraints in the NFF case.

In the NFF model without intermediaries, the spending expansion raises output one-for-one on impact and afterwards the output effect decreases with the government spending impulse. However, in the model with intermediary financing (IF) of the spending expansion, the output response is first of all much smaller on impact: the impact multiplier falls from 1.0 to 0.7 approximately. And second, the output response tails off

\footnotetext{
Gertler, Kiyotaki, and Queralto (2012).

${ }^{10}$ In this variant of the model, borrowing rates co-move through arbitrage behavior by households that choose between bonds and deposits, and the central bank sets the interest rate on bonds.
} 
much more quickly; after about a year the within-period multiplier even turns negative and stays so.

Underlying those effects are the funding pressures that are put on financial intermediaries by a deficit-financed fiscal expansion. The fiscal expansion raises both expected interest rates through the associated tightening of intermediary balance sheet constraints and intermediary balance sheet adjustments. The precise mechanism through which this occurs is explained in Section 3.3 below. As a consequence of the rise in borrowing costs, the demand for capital by intermediate goods firms and thus investment by capital producers is crowded out: in the IF case investment goes down instead of going up as it does in the HHF and NFF cases. The fall in investment is amplified by the financial accelerator mechanism, like in Gertler and Karadi (2011): procyclical variation in intermediary balance sheets amplify the negative effects. Falling investment leads to a falling price of capital, which lowers intermediary net worth and thus further tightens intermediary constraints, which further raises borrowing costs such that investment falls by more, further decreasing asset prices, and so forth. These effects feed through the whole economy as falling wages discourage household labor supply and as the associated tightening of the households' budget constraints depresses consumption.

Interestingly enough, the spending expansion would be (admittedly slightly) more effective if it could be financed by households directly, with the government bypassing financial intermediaries, but with financial frictions in place for private financing needs. This can be seen by comparing the HHF case (no financial frictions for public debt but frictions for private financing needs) with the NFF case where no financial frictions are present at all. Under household financing, the intermediary balance sheet mechanism makes the spending expansion comparatively more effective as the build-up of investment (which occurs under household financing just like in the model without intermediaries) raises the price of capital over time, which in turn eases intermediary balance sheet constraints. As a consequence, an analysis of stimulus policies in a model like Gertler and Karadi (2011), where banks face no leverage constraint on financing acquisitions of public debt but do face such constraints on the financing of claims on the private sector, is likely to lead to the conclusion that the benefits of such policies are enhanced by the relevant financial frictions. The latter is the exact opposite of our results: in our IF case, financial frictions reduce multipliers, eventually even reversing 

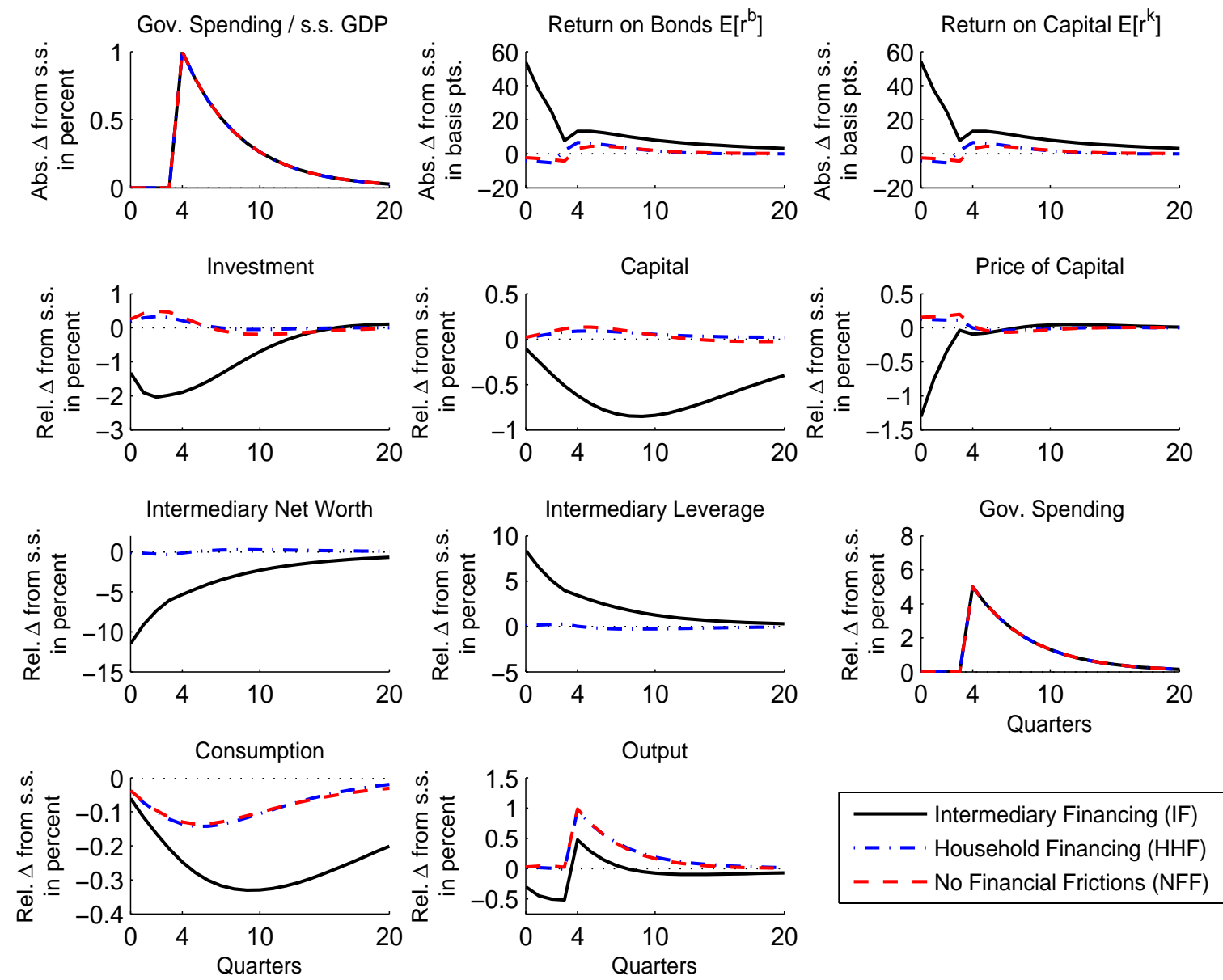

Figure 2: Impulse responses to a pre-announced spending shock I. Note. Announcement in quarter 0 (innovation $\varepsilon_{g, t}^{a}$ ) that government spending is going to increase by $1 \%$ of GDP relative to steady state in quarter 4.

their sign.

\subsection{Effects of a pre-announced spending shock}

The intermediary balance sheet adjustments in interaction with leverage constraints that are at the heart of our model become very clear when we look at the effects of a spending increase that is pre-announced one year in advance. This experiment allows to distinguish the relevant expectational effects from other more direct channels since the direct impact of the spending increase arrives a full four quarters after the announcement. Everything that happens before the actual increase takes place is uniquely driven by expectational effects. The example should also be of substantial practical interest: moving from budgetary plans to implementation takes about a year in most countries.

Figure 2 shows the response of the economy to news in quarter 0 that spending is 

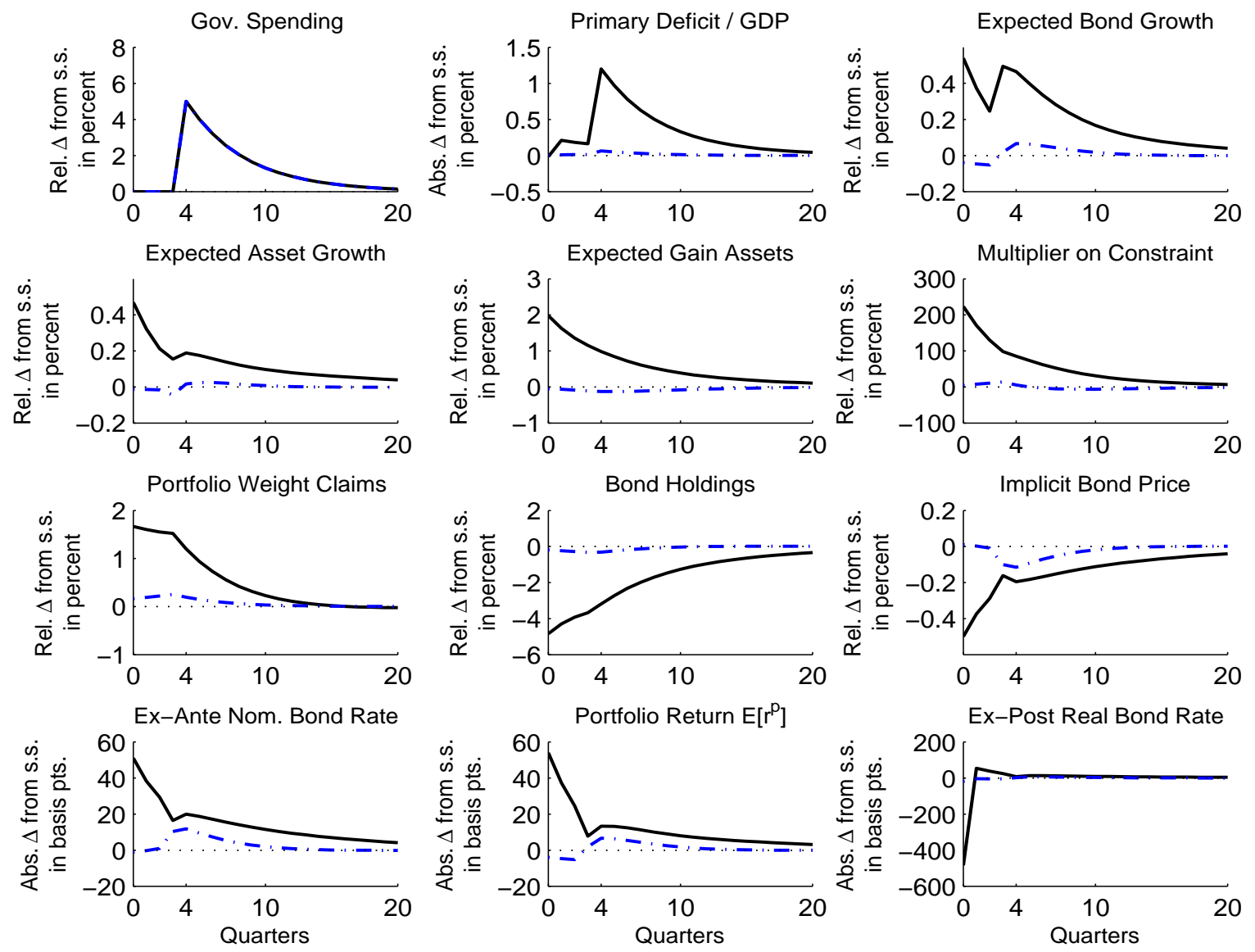

Figure 3: Impulse responses to a pre-announced spending shock II. Note. See Figure 2.

going to increase by $1 \%$ of GDP in quarter 4 . The results show that with intermediary financing of public debt, output falls immediately after the announcement of the spending expansion. The diagrams also highlight the relevant channel: a substantial decline in investment in anticipation of the future tightening that deficit financing will bring. Under direct household financing bypassing the intermediary sector, the spending expansion announcement would have almost no effect on output after the news but before the implementation.

The underlying mechanism is revealed by a closer look at the impulse responses of a second set of variables to the same shock that are shown in Figure 3. A first effect works through a tightening of intermediary balance sheet constraints. The expected future increase in government primary deficits due to the upcoming spending expansion implies higher expected growth rates of bonds and total assets. The intermediaries have an incentive to accumulate assets due to a rise in the expected discounted marginal 
gain of assets. This incentive, however, tightens leverage constraints as indicated by a strong rise in the associated Lagrangian multiplier. The latter restricts intermediary asset demand and raises the costs of credit to both the government and intermediate goods firms during the announcement period (i.e. it raises credit spreads).

A second effect works through intermediary portfolio adjustments. Rising spreads discourage investment and lower the price of capital. Everything else equal, the fall in the price of capital enhances the rise in the expected return on capital. Intermediaries thus shift their portfolios into assets with higher expected returns, i.e. claims on intermediate goods firms. The associated fall in the demand for bonds reduces the implicit bond price and raises the ex-ante nominal interest rate on bonds. The expected real rate on bonds increases, which adds to the rise in the expected overall portfolio return. The increase in the expected portfolio return further enhances incentives to accumulate assets and thus reinforces the first effect discussed above. ${ }^{11}$ Notice that the fall in the demand for bonds is only consistent with an equilibrium if the ex-post real interest rate on bonds falls given a fixed initial supply of bonds by the government. Hence, a planned fiscal expansion in this environment might give an impression of further fiscal space due to low interest rates when, in fact, there is none. Once the expansion takes place output shoots up to give the arguably misleading impression that it is actually effective, albeit only for a short time.

\subsection{Financial crisis and policy responses}

We now analyze the effects of alternative government policy interventions during a simulated financial crisis. The financial crisis itself is simulated through a negative shock to the capital quality parameter $\xi_{t}$, like in Gertler and Karadi (2011), by five percent on impact with autocorrelation coefficient $\rho_{\xi}=0.66$. This shock triggers a response similar in terms of type, magnitude, and duration to the recent crisis. Other initiating shocks are conceivable but the specific type of shock is irrelevant for the qualitative implications of the analysis that follows. Also, and following Gertler and Karadi (2011), we assume that the monetary authority reduces its tendency to smooth interest rates in the face of

\footnotetext{
${ }^{11}$ The portfolio shift into claims tends to dampen the rise in the expected return on capital. With higher portfolio adjustment costs, this dampening effect becomes weaker and the crowding-out effect stronger. By allowing for low adjustment costs, our results thus rather fall on the conservative side.
} 
the shock, to capture the notion that monetary policy tends to be more aggressive during a financial crisis. ${ }^{12}$ As seen in the figures below, absent any government intervention (the black solid line), the deterioration in intermediary asset quality produces a sharp recession with a peak output decline of more than five percent, as intermediary net worth drops and credit tightens, leading to a sharp rise of the credit spread. Investment initially drops sharply and takes more than two years to recover; as a consequence, output takes more than four years to reach pre-shock levels again.

We consider the following government policies in response: (i) an immediate deficitfinanced spending stimulus; (ii) a similar stimulus, but four quarters delayed; (iii) immediate transfers to intermediaries; (iv) delayed transfers; (v) zero-interest loans with delayed repayment; also to intermediaries (vi) loans to intermediaries at penalty interest rates; (vii) and finally as a set of benchmarks, partly and fully tax-financed spending stimuli. ${ }^{13}$ This set of policies helps elucidating the structure and implications of the model presented, but also suitably captures the main fiscal measures applied during the recent crisis. The policies are either financed by issuing bonds to intermediaries or, to establish a benchmark against which to judge the impact of deficit financing under financial fragility, by raising lump-sum taxes directly from households without resorting to the intermediaries.

\subsubsection{Fiscal stimulus after a capital quality shock}

Figure 4 illustrates the effects of a countercyclical, persistent spending stimulus of two percent of GDP that occurs immediately when the shock hits. The results show that the deficit-financed demand stimulus dampens the initial decline in output by more than one percentage point relative to the no intervention case. But after about a year, the fall in output turns slightly stronger than without government intervention, and it remains more negative afterwards. This effect is due to a larger fall in investment. This further decline in investment is caused by the additional rise in the credit spread due to the tightening of leverage constraints because of the increased government borrowing. The fall in investment and a larger decline in consumption (due to a higher future

\footnotetext{
${ }^{12}$ The smoothing parameter $\rho_{r}$ in the Taylor rule is reduced by half but not more so that nonnegativity constraints on nominal interest rates remain satisfied.

${ }^{13}$ To make the results comparable, the different policy measures are scaled to have the same size relative to GDP on impact by adjusting the feedback parameters $\varsigma$ and $\varkappa$ accordingly.
} 

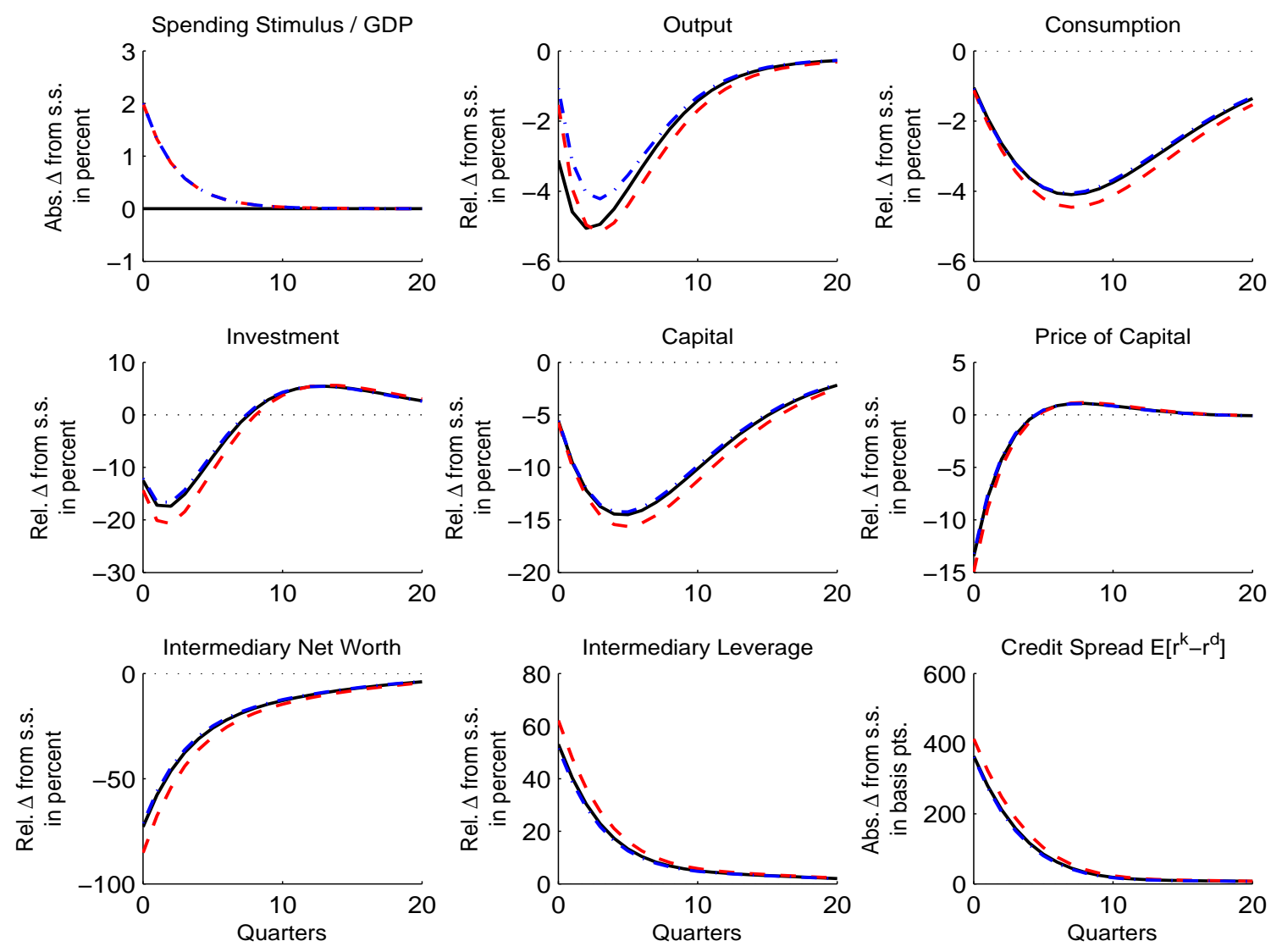

Figure 4: Crisis policy I - immediate spending stimulus. Note. Initiating shock is unexpected decline in the quality of capital by five percent relative to steady state in quarter 0 ; autocorrelation coefficient $\rho_{\xi}=0.66$.

tax burden) eventually more than offset the initial output gain from the additional government spending.

What happens if the spending stimulus occurs relatively late during the recession? In Figure 5 the policy is implemented with a delay of one year after the initial shock occurs, but fully anticipated. This is by far the more likely case in practice, if only because of standard budget approval and implementation procedures. With this added delay, the deficit-financed stimulus is actually counterproductive: the fall in output is amplified. The peak decline in output now reaches almost six percent. The reason is that credit tightens immediately in the face of the upcoming spending expansion, as discussed in Section 3.3. A similar fall in investment as under an early fiscal expansion thus takes place, but the actual stimulus arrives later, so the initial decline in output is further amplified instead of partially offset.

Notice that in both cases the stimuli would be more effective if the leverage constraint 

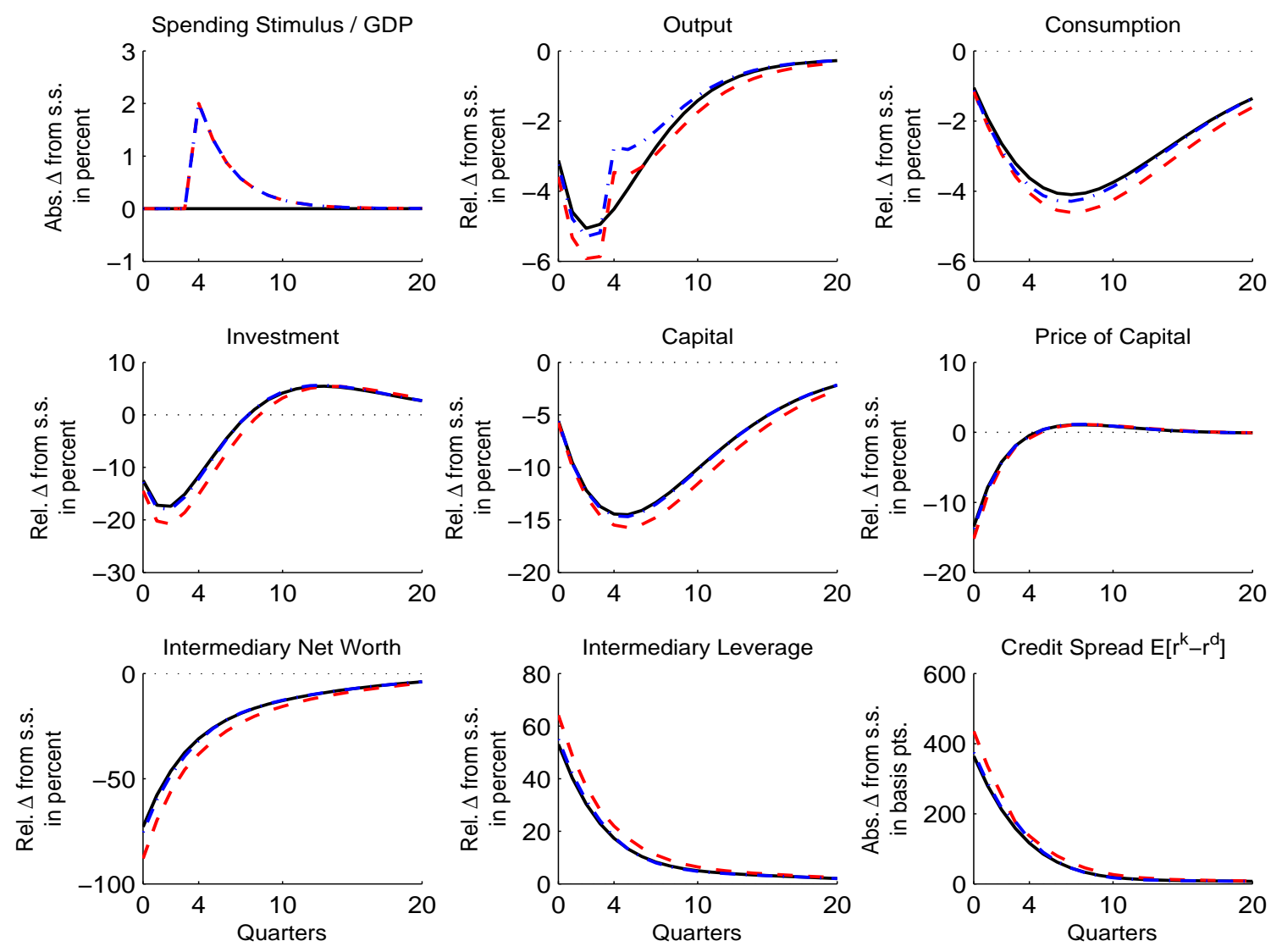

— No Government Intervention - - - Intermediary Financing (IF) : - : - Household Financing (HHF)

Figure 5: Crisis policy II - delayed spending stimulus. Note. See Figure 4.

can be bypassed, as in the benchmark HHF (household financing) case. The reason for this result is similar to the discussion in Sections 3.2 and 3.3, in the HHF case credit conditions do not tighten and private sector investment is not crowded out.

\subsubsection{Financial sector support measures}

Consider next the effects of financial sector support measures, in the form of transfers to intermediaries under various assumptions about repayment terms. The responses of the credit spread $E_{t}\left[r_{t+1}^{k}-r_{t+1}^{d}\right]$ and output under pure transfers, immediate or delayed by one year, and zero-interest loans with delayed repayment after one year are shown in Figure 6 . The charts in the first two rows show that immediate pure transfers moderate the recession. Delayed pure transfers do that also, even before their actual implementation, because of the forward-looking character of the intermediary constraints. In both cases, the transfers dampen the rise in the spread by raising intermediary net worth.

The third row considers the case of zero-interest loans that are repaid after four 

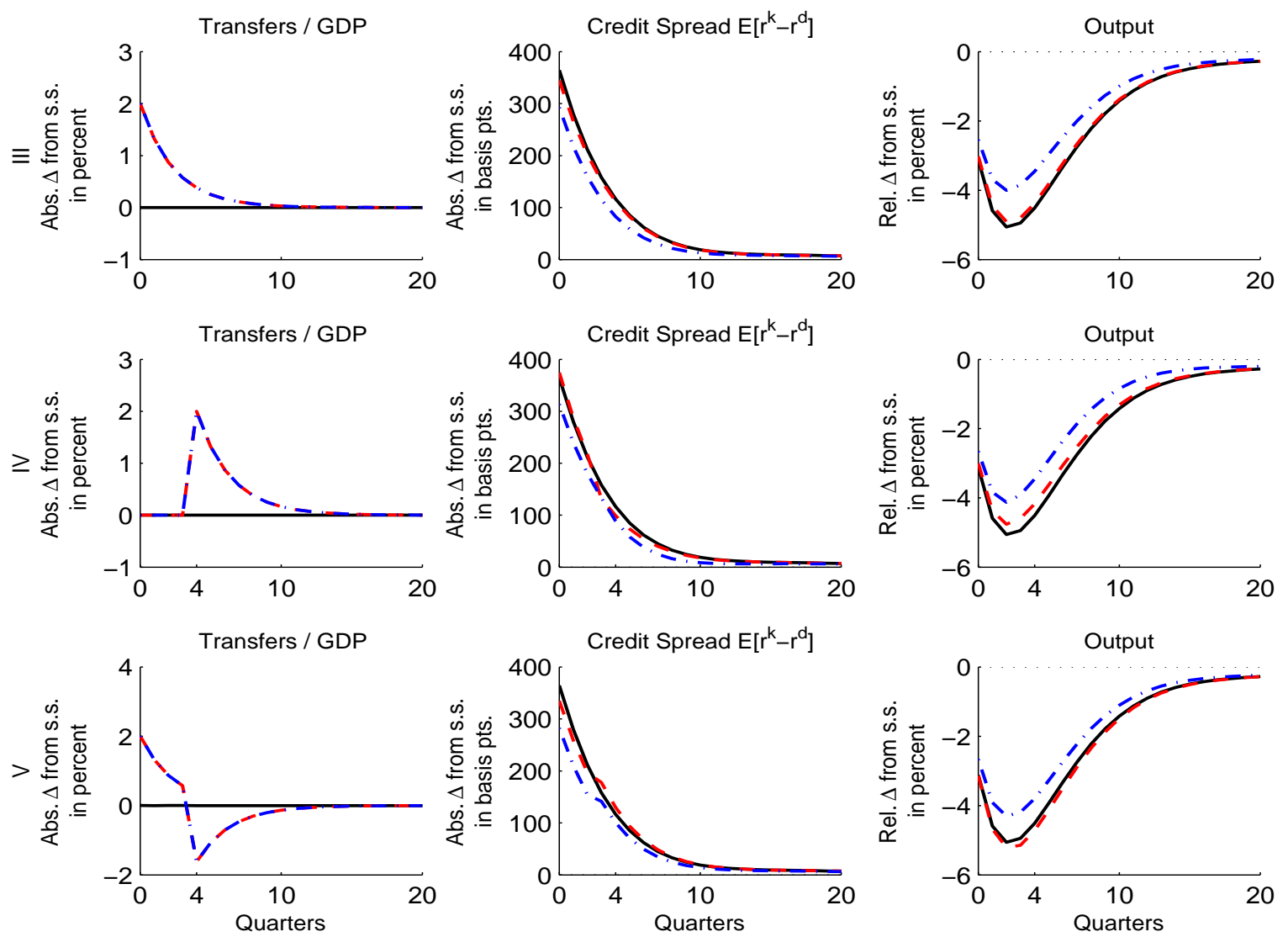

No Government Intervention - - - Intermediary Financing (IF)

$\cdot-\cdot \cdot$ Household Financing (HHF)

Figure 6: Crisis policies III to $\mathrm{V}$ - immediate transfers to intermediaries, delayed transfers, and zero interest loans with delayed repayment. Notes. III: immediate transfers; IV: delayed transfers; V: zero interest loans; see Figure 4.

quarters. According to the results, such loans are not effective in dampening the crisis under deficit financing. In the benchmark case of household financing, however, the loans would be effective in reducing the output loss.

We can also go a step further and look at loans that need to be repaid at penalty interest rates. Figure 7 shows the dynamics due to the capital quality shock when the loans need to be repaid after sixteen quarters, at zero interest or at one hundred and two hundred percent penalty rates. ${ }^{14}$ The figure also shows the dynamics without government intervention as the reference case. The dynamics of the cases with different repayment rates have some surprising characteristics. The downturn is dampened during the initial quarters, and, surprisingly, the more the higher the repayment, but around the time of the repayment the recession actually worsens, in a double-dip fashion, and

\footnotetext{
${ }^{14}$ The delay of sixteen quarters is chosen because at that point the crisis is arguably over, thus motivating repayment of temporary support measures.
} 

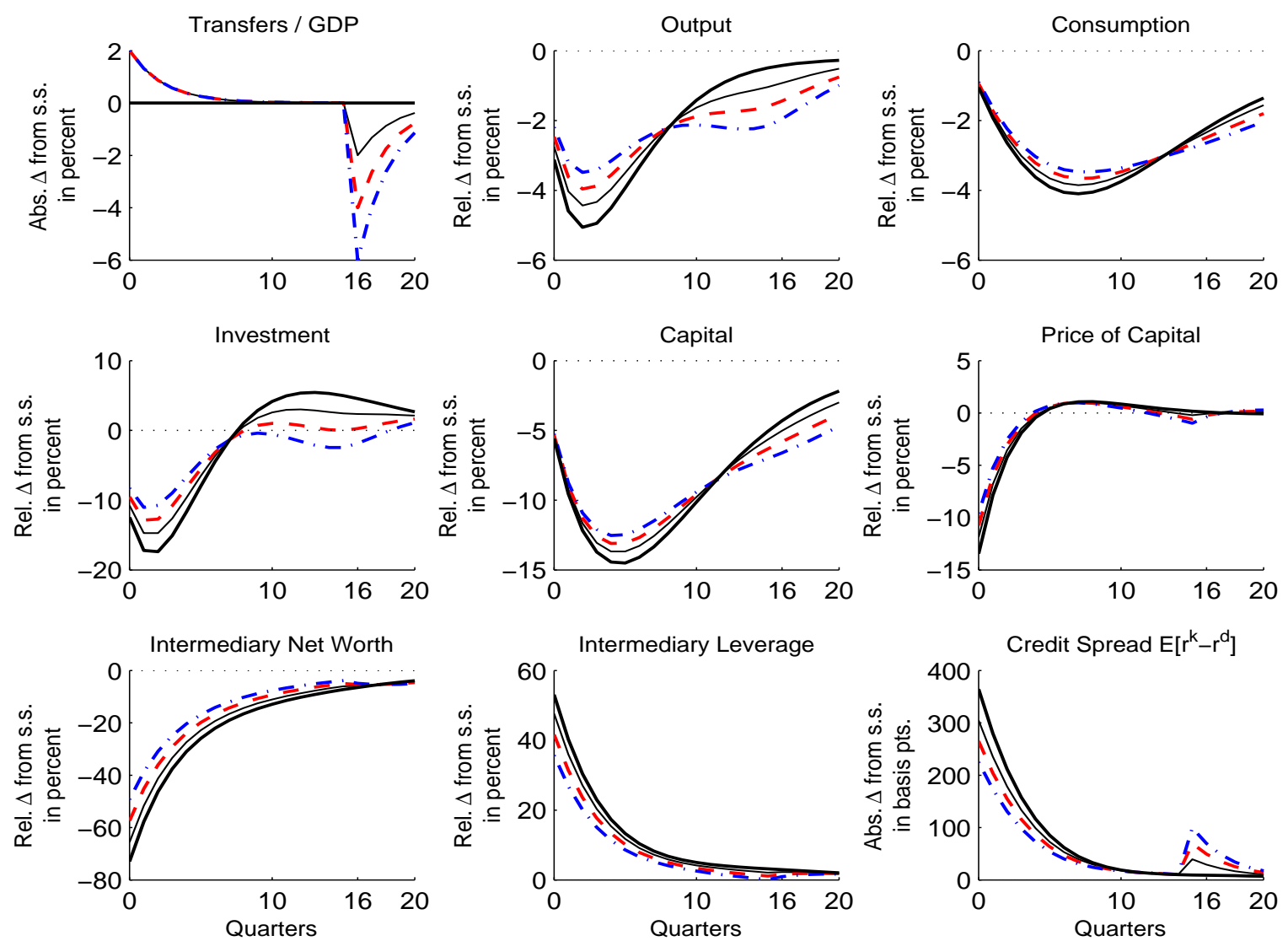

Z Zero Interest ---100 Perc. Interest $\cdot-\cdot-\cdot 200$ Perc. Interest

No Gov. Intervention

Figure 7: Crisis policy VI - loans at penalty interest rates. Note. See Figure 4.

the more so the more stringent the repayment conditions: the second dip is larger the larger the repayment requirements. The credit spread shows spikes around the time when the repayments are due in the four different cases.

It may seem odd that the initial output response to the crisis is more dampened the higher the eventual repayment penalty rate. The reason is the more pronounced future credit tightening anticipated to take place around repayment dates with higher repayment penalties. Capital producing firms anticipate the future tightening of credit conditions and the associated future fall in the price of capital. The capital producers therefore increase their initial investment, given relatively higher resale prices, which leads to an accelerated rise in the price of capital that eases balance sheet constraints on financial intermediaries and thus tends to dampen the initial crisis. 

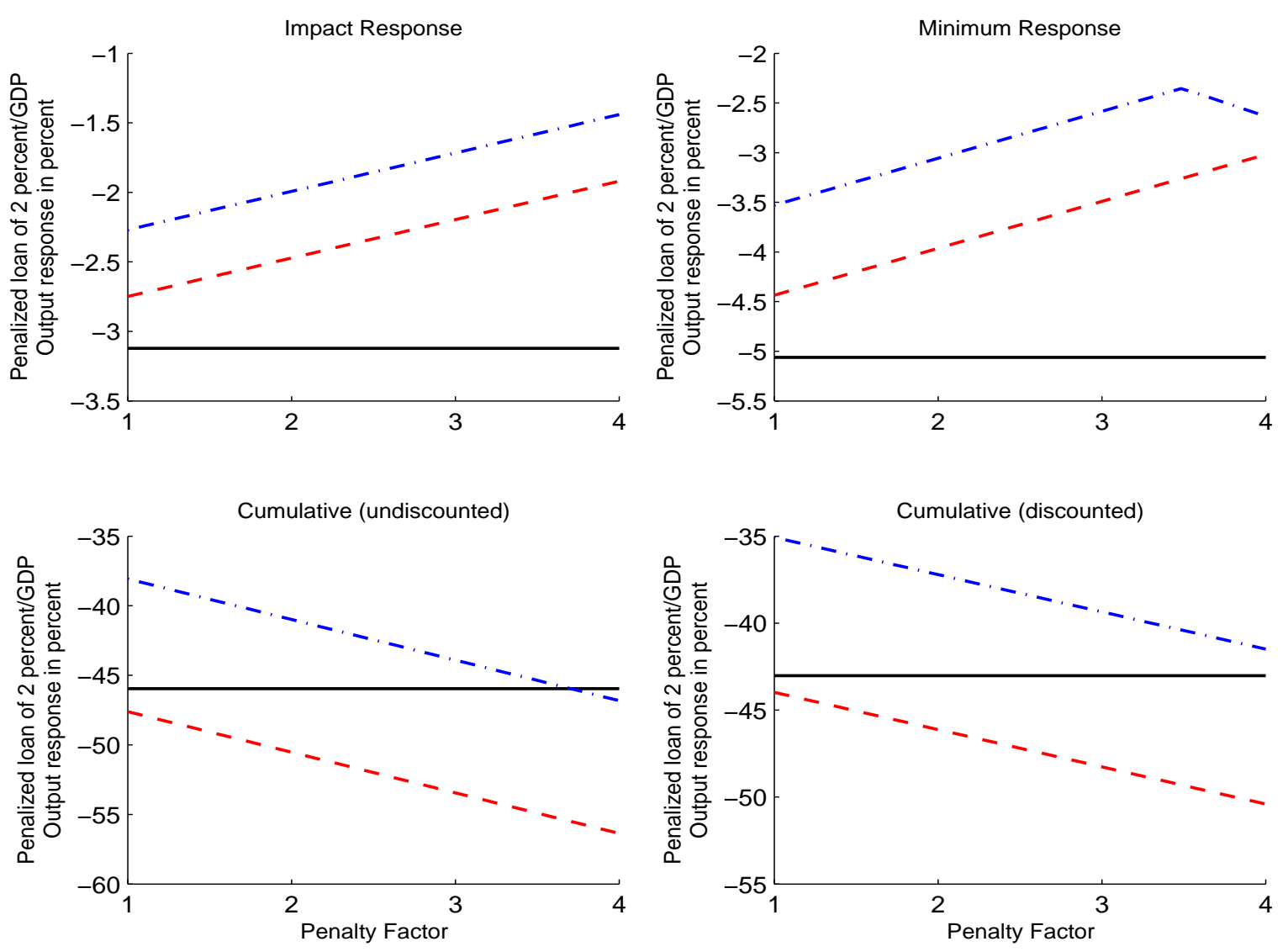

- No Government Intervention - - - Intermediary Financing (IF)

Figure 8: Output gains from penalty-rate loans. Notes. Crisis experiment as in Figure 4; $2 \%$ of GDP initial loans with delayed repayment at penalty rates; penalty factor $x$ : $100 \times(x-1)$ percent penalty interest rate.

\subsubsection{Output gains from government policies}

Can the initial stabilizing effects during the crisis potentially suffice to generate overall output stabilization gains from high penalty rate loans? Figure 8 plots measures of output gains against the penalty factor in loan repayment, which occurs after sixteen quarters in all cases. The four charts show the impact responses, the minimum responses, and the undiscounted and discounted cumulative responses of GDP under both deficitfinanced loans (IF, dashed lines) and household-financed loans (HHF, dashed-dotted lines) relative to the case of no intervention (solid lines). ${ }^{15}$ The loans are again scaled to two percent of GDP. According to the impact and minimum responses, under bothm intermediary deficit financing and household financing, providing liquidity is an effective

\footnotetext{
${ }^{15}$ Denote as $\breve{y}_{k}$ the percentage deviation of output from its steady state value at horizon $k=$ $0,1,2, \ldots, T$ with the government intervention. The measures are calculated as follows: impact responses $\breve{y}_{0}$; minimum responses $\min _{k} \breve{y}_{k}$; undiscounted cumulative responses $\sum_{k=0}^{T} \breve{y}_{k}$; discounted cumulative responses $\sum_{k=0}^{T} \beta^{k} \breve{y}_{k}$, where $\beta$ is the household subjective discount factor. We set $T=1000$.
} 

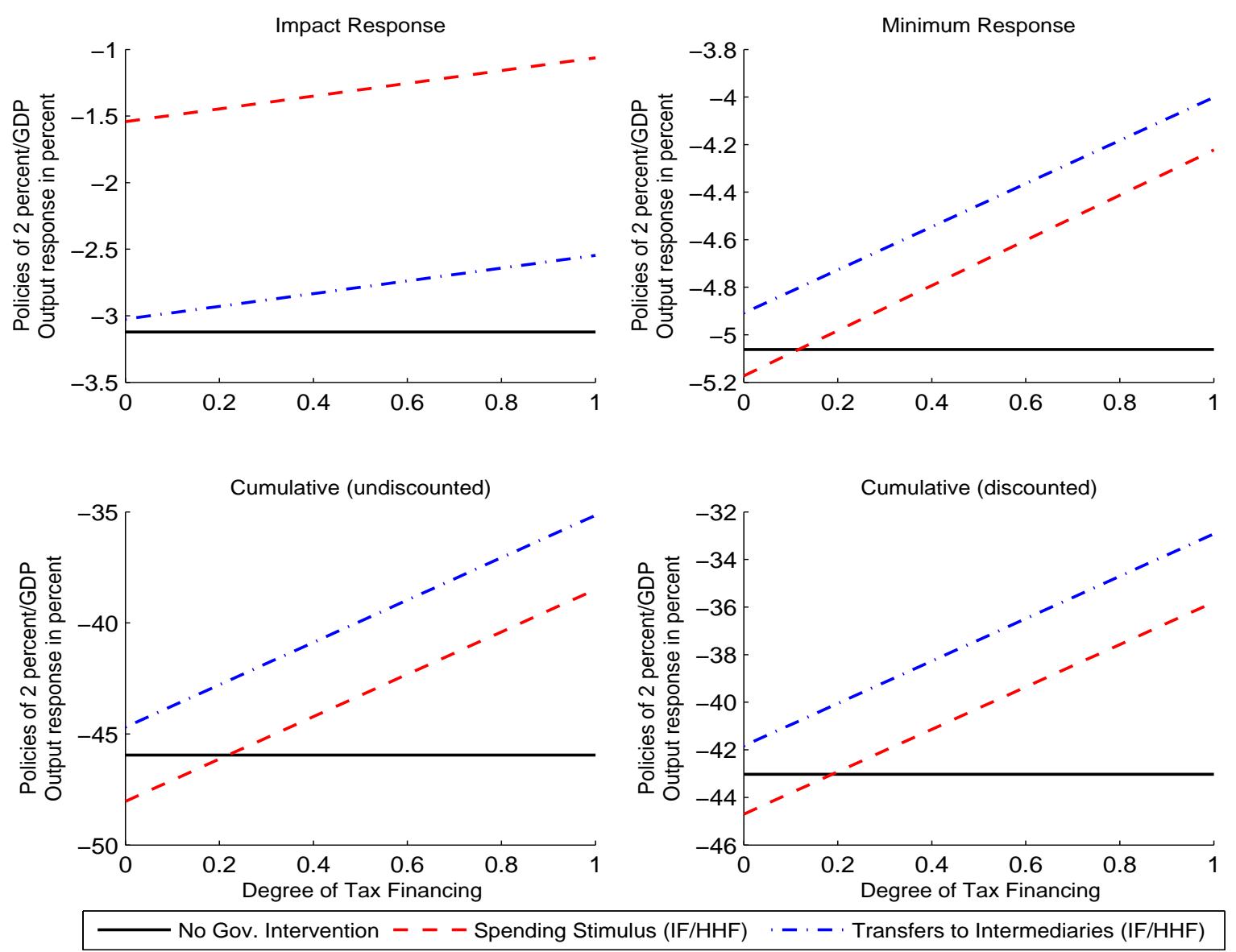

Figure 9: Output gains from stimuli and transfers under mixed financing. Notes. Crisis experiment as in Figure 4; $2 \%$ of GDP initial spending stimuli; degree of tax financing $x$ : $100 \times x$ percent household financing, $100 \times(1-x)$ percent intermediary financing.

means to dampen the crisis recession for all values of the penalty factor considered. The reason is that some of the output loss is shifted towards later periods by the extension of loans at high interest rates to the banking sector, due to (the anticipation of) rising credit spreads and thus falling investment at the time of the repayment. However, both undiscounted and discounted output gains are actually negative in the case of intermediary finance. But without the increasing financial tightness that intermediary financing leads to, even very large penalty factors would still bring overall cumulative stabilization gains! Under intermediary financing, on the other hand, there are no overall stabilization gains according to both cumulative measures considered. ${ }^{16}$

Summing up, a straightforward analysis of financial sector policies in a model similar to Gertler and Karadi (2011), without intermediary financing of government deficits,

\footnotetext{
${ }^{16}$ The kink in the upper right chart is due to the fact that at that point, for relatively high penalty factors, the output drop at the time of the repayment turns larger than the minimum response during the crisis.
} 
could lead to a rather odd conclusion: overall output stabilization gains are possible when temporary support measures are repaid after some time at huge penalty rates. When considering deficit financing by intermediaries, however, the relatively small overall gains from deficit-financed policies should lead to more cautious predictions, more in line with common sense intuition.

As a final step, we examine stabilization gains from demand stimulus as well as transfers to intermediaries depending on the degree of deficit financing as determined by $\kappa_{g}$ and $\kappa_{n}$. This final experiment serves to compare whether there is some critical point at which the benefits from these policies surpass the costs due to the tightening of intermediary constraints, in view of the core question of this paper. According to the results in Figure 9, both measures are least effective under full deficit financing. Transfers, hypothetically perhaps, can bring stabilization gains even under full intermediary deficit financing. However, already for moderate degrees of household financing above 20 percent, the stimulus is also able to dampen the recession (cf. the minimum responses) and moderate the overall output loss (cf. the cumulative responses). This result again emphasizes the importance of taking the precise financing mode of fiscal policy into account when deciding on policy measures in a situation of financial distress.

\section{Related empirical evidence}

This section provides a brief review of the empirical evidence that is relevant to our study. The related evidence can be grouped into (a) results from fiscal VAR studies on the effects of government spending or goods purchases, in particular on private investment, (b) findings of cross-sectional studies that investigate the impact of financial sector policies and fiscal stimulus during financial crises, and (c) results from empirical studies looking at the effects of fiscal finances on interest rates.

Among the first group of studies, both structural VAR (SVAR) methods and eventstudy approaches point towards negative effects of government spending on private investment. On the SVAR side, Blanchard and Perotti (2002) find that investment is consistently crowded out by government spending shocks in the U.S. over the period 1960Q1-1997Q4, with a peak decline of up to one percent due to a 1\% of GDP spending increase. Using a yearly panel VAR on 18 OECD countries over the period 1960-1996, 
Alesina, Ardagna, Perotti, and Schiantarelli (2002) also find a sizable negative effect of public spending (particularly public wages) on investment, a one percentage point increase in the primary spending-to-GDP ratio leading to a fall in the investment-to-GDP ratio of 0.15 percentage points on impact and to a cumulative fall of 0.74 percentage points after five years. On the side of event studies, identifying spending shocks based on war dates and professional forecasts, Ramey (2011) finds that after a positive defense news shock in the U.S. both non-residential and residential investment fall significantly, with peak effects of up to -1 percent (non-residential investment) and -1.5 percent (residential investment). Shocks identified based on professional forecast errors over the period 1969-2008 indicate even stronger falls of -1.5 percent and -3.5 percent, respectively, as well as a medium-term decline in output.

Our model predicts stronger crowding-out effects of spending-based fiscal expansions on investment than most of the above VAR studies (see Figures 1 and 2). ${ }^{17}$ The qualitative predictions are however similar. The quantitative differences should not come as a big surprise as the model mainly describes business cycles in times of financial distress, whereas the above studies look instead at sample averages also including "normal"times. So the results reported in Mulas-Granados, Baldacci, and Gupta (2009) are possibly more relevant. They estimate the effects of fiscal policy interventions during 118 episodes of banking crises in a cross-section of developed and emerging countries. In line with our results of Section 3.4, they find that financial sector policies can shorten such crises whereas fiscal stimulus going along with such policies can have stabilizing effects, but not for countries where fiscal policy is subject to funding constraints. A similar conclusion is reached by Ilzetzki, Mendoza, and Végh (2010); based on a quarterly dataset for 20 developed and 24 developing countries over the period 1960-2007, they find that during episodes where government debt was higher than $60 \%$ of GDP, spending multipliers are not statistically different from zero on impact and negative (and statistically significant) in the long run.

Finally, a recent study on the effects of fiscal finances on interest rates has been conducted by Laubach (2009), who estimates the effects of U.S. government debt and deficits on Treasury yields, isolating those effects from other factors affecting interest

\footnotetext{
${ }^{17}$ The fall in investment in Figure 1 implies a 0.41 percentage points decline in the investment-to-GDP ratio on impact and a cumulative fall of approximately three percentage points after five years.
} 
rates (e.g. due to countercyclical monetary policy and automatic fiscal stabilizers) by focusing on the relation between long-horizon expectations of both interest rates and fiscal variables. According to Laubach (2009), the idea is that measures of expectations hold out the prospect of uncovering causal effects from fiscal variables to interest rates. Laubach (2009) concludes that the effects of fiscal variables on interest rates are statistically significant and economically relevant; in particular, for the period 1976-2006 an increase in the projected deficit-to-GDP ratio by one percentage point raises forward rates five and more years into the future by about 25 basis points. This result is in line with our findings shown in Figures 1 and 2. Other related studies also tend to find statistically and economically significant effects of deficits on interest rates (see Canzoneri, Cumby, and Diba, 2002; Elmendorf, 1993; Wachtel and Young, 1987).

\section{Conclusion}

After a wave of calls for fiscal stimulus to lift distressed economies out of the recession induced by the global financial crisis, economic growth did pick up after the implementation of large fiscal stimulus packages in the U.S., China and Western Europe. Many observers concluded that the fiscal stimuli were effective; see, for instance, Romer (2009) or Romer and Bernstein (2009), and also CBO (2009), IMF (2009), and OECD (2009). However, despite reduced credit spreads and diminishing job losses, the recovery turned out to be less robust than originally hoped, also in the U.S. where, at least in absolute size, the largest package was adopted (see Mankiw, 2009). Doubts about the impact of the implemented policies have started to come up and many observers have asked why the stimulus was not more effective (e.g. Adams and Gangnes, 2010).

Our model provides one possible answer to this question. Key to our answer is the fact that it takes time to implement announced measures: in the case of the U.S., it took more than one year between the first plans for fiscal stimulus (cf. Summers, 2008) and the enactment of the American Recovery and Reinvestment Act of 2009. Our results suggest that an announced but delayed stimulus of this type can appear to be effective once it occurs, lowering credit spreads and raising output growth. However, the announcement of the stimulus will deepen the crisis before the implementation of any measures has taken place. Moreover, our analysis suggests that after its direct demand 
effects are realized, a stimulus package will be followed by lower medium-term growth than without any government interventions.

At the core of our analysis are interactions between frictions in the banking system and the placement of public sector debt. Bank holdings of public debt are very important in most emerging market economies and are playing an increasingly crucial role in the macroeconomics of the euro area. We extend the recent literature on the macroeconomic impact of leverage constraints on banks (see, in particular, Gertler and Karadi, 2011; Gertler, Kiyotaki, and Queralto, 2012) by introducing portfolio choice for banks, who in our setup can hold both public debt and claims on the private corporate sector. This introduces a new crowding-out channel if leverage constraints apply to all their assets, and not just to the financing of claims on the private sector as in Gertler and Karadi (2011) and Gertler, Kiyotaki, and Queralto (2012).

Our analysis supports the notion that even a timely conceived but slowly implemented stimulus can have undesirable crowding-out effects up front that may in fact be large enough to eventually offset its desired impact altogether. We highlight in this paper a channel through which more than one-for-one crowding out may happen that is very different from the example on the unavoidability of distortionary taxation, another mechanism through which crowding out of government expenditure can occur that has been stressed in the literature. ${ }^{18}$

If fiscal stimuli are less effective than commonly thought, what can governments do to stabilize the economy in times of financial distress? Our results confirm that financial sector policies can be effective tools but caution that there a lot depends on the way they are financed. We show that it makes a great deal of difference whether liquidity is provided through straight transfers (or the taking of equity stakes) or alternatively are financed through loans to the intermediaries that are supported. Governments may choose not to make transfers (for state support or moral hazard concerns), and/or may decide against taking equity stakes, possibly for ideological reasons; that leaves the alternative of providing funds in the form of loans. We show that if that route is chosen, the ensuing dynamics can be quite complex and possibly perverse. An important condition for loans to intermediaries to be effective is that repayments are agreed to occur

\footnotetext{
${ }^{18}$ See, for instance, Drautzburg and Uhlig (2011), or Coenen, Erceg, Freedman, Furceri, Kumhof, Lalonde, Laxton, Lindé, Mourougane, Muir, Mursula, de Resende, Roberts, Roeger, Snudden, Trabandt, and in 't Veld (2012).
} 
with a significant delay. If they need to be repaid relatively early, the anticipation of the funding pressures that financial intermediaries will face once repayment is due may offset the positive impact of the initial liquidity infusion. And even if repayment periods are long enough, we show that very high penalty rates of interest may still offset the positive impact of the bailout: short-term stabilization gains can then be followed by a negative dip around repayment dates that is larger when the repayment penalty is more punitive.

Finally, we would like to emphasize that the model discussed in this paper highlights specific mechanisms that we consider most relevant for an analysis of government policies in times of financial distress, while neglecting other well-known macroeconomic interventions, such as tax cuts, boosts to public investment plans, transfers to liquidityconstrained consumers, labor market policies, and so forth. These other policies are however well-studied by now, and extensions of our model into that direction are unlikely to change our main conclusions or to add much understanding to the key mechanisms highlighted in this paper.

\section{References}

Adams, F. G., and B. Gangnes (2010): "Why Hasn't the US Economic Stimulus Been More Effective? The Debate on Tax and Expenditure Multipliers," Working Papers 201010, University of Hawaii at Manoa, Department of Economics.

Alesina, A., S. Ardagna, R. Perotti, and F. Schiantarelli (2002): "Fiscal Policy, Profits, and Investment," American Economic Review, 92(3), 571-589.

Bean, C., M. Paustian, A. Penalver, and T. Taylor (2010): "Monetary Policy after the Fall," Paper presented at the Federal Reserve Bank of Kansas City Annual Conference, Jackson Hole, Wyoming, August 28, 2010.

Blanchard, O., and R. Perotti (2002): "An Empirical Characterization of the Dynamic Effects of Changes in Government Spending and Taxes on Output," The Quarterly Journal of Economics, 117(4), 1329-1368.

Bohn, H. (1998): "The Behavior of U.S. Public Debt and Deficits," The Quarterly Journal of Economics, 113(3), 949-963. 
Bonaparte, Y., And R. Cooper (2009): "Costly Portfolio Adjustment," NBER Working Papers 15227, National Bureau of Economic Research, Inc.

Calvo, G. A. (1983): "Staggered prices in a utility-maximizing framework," Journal of Monetary Economics, 12(3), 383-398.

Canzoneri, M. B., R. E. Cumby, and B. T. Diba (2002): "Should the European Central Bank and the Federal Reserve be concerned about fiscal policy?," Federal Reserve Bank of Kansas City Proceedings, pp. 333-389.

CBO (2009): "Estimated Impact of the American Recovery and Reinvestment Act on Employment and Economic Output as of September 2009," U.S. Congressional Budget Office, November 2009.

Christiano, L., And D. Ikeda (2011): "Government Policy, Credit Markets and Economic Activity," NBER Working Papers 17142, National Bureau of Economic Research, Inc.

Christiano, L. J., M. Eichenbaum, and C. L. Evans (2005): "Nominal Rigidities and the Dynamic Effects of a Shock to Monetary Policy," Journal of Political Economy, 113(1), 1-45.

Christoffel, K., G. Coenen, and A. Warne (2008): "The new area-wide model of the euro area - a micro-founded open-economy model for forecasting and policy analysis," Working Paper Series 944, European Central Bank.

Coenen, G., C. J. Erceg, C. Freedman, D. Furceri, M. Kumhof, R. Lalonde, D. Laxton, J. L. Lindé, A. Mourougane, D. V. Muir, S. Mursula, C. de Resende, J. M. Roberts, W. Roeger, S. M. Snudden, M. TraBANDT, AND J. IN 'T VELD (2012): "Effects of Fiscal Stimulus in Structural Models," American Economic Journal: Macroeconomics, , 4(1), 22-68.

Drautzburg, T., and H. Uhlig (2011): "Fiscal Stimulus and Distortionary Taxation," NBER Working Papers 17111, National Bureau of Economic Research, Inc.

ECB (2010): "Assessment of the risks of EU bank's exposures to sovereign debt as revealed by the EU-wide stress-testing exercise," in Financial Stability Review, December 2010, chap. 4, pp. 84-86. European Central Bank. 
Elmendorf, D. W. (1993): "Actual Budget Deficit Expectations and Interest Rates," Harvard Institute of Economic Research Working Papers 1639.

Gertler, M., And P. Karadi (2011): "A model of unconventional monetary policy," Journal of Monetary Economics, 58(1), 17-34.

Gertler, M., and N. Kiyotaki (2010): "Financial Intermediation and Credit Policy in Business Cycle Analysis," in Handbook of Monetary Economics, ed. by B. M. Friedman, and M. Woodford, vol. 3, chap. 11, pp. 547-599. Elsevier.

Gertler, M., N. Kiyotaki, and A. Queralto (2012): "Financial Crises, Bank Risk Exposure and Government Financial Policy," Journal of Monetary Economics, forthcoming.

Ilzetzki, E., E. G. MendozA, And C. A. VÉGh (2010): "How Big (Small?) are Fiscal Multipliers?," NBER Working Papers 16479, National Bureau of Economic Research, Inc.

IMF (2009): "The Global Recession is Ending," in World Economic Outlook, October 2009, chap. 1, pp. 1-3. International Monetary Fund.

- (2010): "Sovereign Risks and Financial Fragilities," in Global Financial Stability Report, October 2010, chap. 1, pp. 4-13. International Monetary Fund.

Laubach, T. (2009): "New Evidence on the Interest Rate Effects of Budget Deficits and Debt," Journal of the European Economic Association, 7(4), 858-885.

Luttmer, E. G. J. (1999): "What Level of Fixed Costs Can Reconcile Consumption and Stock Returns?," Journal of Political Economy, 107(5), 969-997.

Mankiw, N. G. (2009): "Tax Cuts Might Accomplish What Spending Hasn't," New York Times, December 12, 2009.

Mulas-Granados, C., E. Baldacci, and S. Gupta (2009): "How Effective is Fiscal Policy Response in Systemic Banking Crises?," IMF Working Papers 09/160, International Monetary Fund.

OECD (2009): "OECD Economic Outlook November 2009," Organization for Economic Co-operation and Development. 
Ramey, V. A. (2011): "Identifying Government Spending Shocks: It's all in the Timing," The Quarterly Journal of Economics, 126(1), 1-50.

Romer, C. D. (2009): "Fiscal Policy and Economic Recovery," Business Economics, $44(3), 132-135$.

Romer, C. D., And J. Bernstein (2009): "The Job Impact of the American Recovery and Reinvestment Plan," U.S. Council of Economic Advisors, Office of the Vice President-Elect, January 8, 2009.

Summers, L. H. (2008): "Fiscal Stimulus Issues," Testimony before the U.S. Joint Economic Committee, January 16, 2008.

TAYlor, J. B. (1993): "Discretion versus policy rules in practice," Carnegie-Rochester Conference Series on Public Policy, 39(1), 195-214.

Wachtel, P., And J. Young (1987): "Deficit Announcements and Interest Rates," American Economic Review, 77(5), 1007-12.

Yun, T. (1996): "Nominal price rigidity, money supply endogeneity, and business cycles," Journal of Monetary Economics, 37(2-3), 345-370. 


\section{A Steady State Solution}

This appendix derives the solution for the non-stochastic steady state of the model and shows that the incentive constraint is binding in the steady state. For simplicity, the solution is derived for a zero inflation steady state. This is achieved by setting the target inflation rate in the monetary policy rule accordingly, i.e. $\bar{\pi}=1$; the Taylor rule then implies that $\pi=1$. The steady state real interest rate on deposits and the steady state risk-free nominal interest rate then follow from the household's consumption Euler equation and the corresponding Fisher relation:

$$
r^{d}=\beta^{-1}-1, \quad r^{n}=r^{d}
$$

Further, by the capital producer's first-order condition, the relative price of capital equals one in the steady state: $q=1$.

To solve for the variables that are determined by the financial intermediaries' problem, we guess and verify that there is an equilibrium with $r^{k}-r^{d}=r^{b}-r^{d}=\Gamma>0$. We also take as given the total leverage ratio $\phi$ by calibrating $\chi$, the average survival time of bankers $\Theta=1 /(1-\theta)$ by setting $\theta=(\Theta-1) / \Theta$ and the interest rate spread $\Gamma$ by calibrating $\lambda$. As $r^{k}=r^{b}$, we then obtain from the portfolio manager's first-order condition that $\omega=\bar{\omega}$. Given $r^{d}$, we also obtain $r^{k}=r^{d}+\Gamma$ and $r^{b}=r^{k}$. From the equation for $r^{p}$, it follows that $r^{p}=r^{k}$. We further obtain

$$
\varrho=0, \quad v=\frac{\beta(1-\theta)\left(1+r^{p}\right)}{1-\beta \theta}, \quad \eta=\frac{\beta(1-\theta)\left(1+r^{d}\right)}{1-\beta \theta}, \quad \lambda=v+\frac{(1-\phi) \eta}{\phi} .
$$

We also have

$$
\chi=1-\theta\left(\Gamma \phi+1+r^{d}\right)
$$

Next, we see that the incentive constraint indeed binds in the steady state, because

$$
\lambda-v+\eta=\eta / \phi=(1-\theta) \beta\left(1+r^{d}\right) \phi^{-1}(1-\theta \beta)^{-1}>0 .
$$

We now solve for the production allocation. From the price setting equations, for a zero inflation steady state, we have

$$
\pi^{*}=\Delta=1, \quad \Xi_{1}=m \lambda y(1-\beta \psi)^{-1}, \quad \Xi_{2}=\lambda y(1-\beta \psi)^{-1},
$$

such that $\Xi_{1} / \Xi_{2}=m$. The first-order condition of the intermediate goods firms' price-setting problem therefore implies that $m=(\epsilon-1) / \epsilon$. As $\Delta=1$ and $a=\xi=1$, we will use that 
steady state final output is $y=k^{\alpha} h^{1-\alpha}$. Further, the steady state real wage can be derived from the marginal cost equation, given $r^{k}$ and $m$ :

$$
w=\left[\alpha^{\alpha}(1-\alpha)^{1-\alpha} m\left(r^{k}+\delta\right)^{-\alpha}\right]^{\frac{1}{1-\alpha}}
$$

The capital-labor ratio is then

$$
k / h=\alpha(1-\alpha)^{-1} w\left(r^{k}+\delta\right)^{-1} .
$$

By the resource constraint, the steady state ratio of consumption over output is

$$
c / y=1-i / y-g / y
$$

where $i / y$ and $g / y$ are taken as given. The household's remaining first-order conditions for consumption and hours worked then imply that

$$
\lambda=(1-\beta v)[(1-v)(c / y) y]^{-1}, \quad h=\left\{(1-\beta v) w[(1-v)(c / y) y]^{-1}\right\}^{\frac{1}{\varphi}} .
$$

Steady state final output then follows from $y=(k / h)^{\alpha} h$, or

$$
y=(k / h)^{\frac{\alpha \varphi}{1+\varphi}}\left\{(1-\beta v) w[(1-v)(c / y)]^{-1}\right\}^{\frac{1}{1+\varphi}} .
$$

such that $\lambda$ and $h$ can be computed from (A.1). Steady state consumption, investment, and government spending are thus

$$
c=(c / y) y, \quad i=(i / y) y, \quad g=(g / y) y
$$

The government spending process can then be specified such that $g / y$ can be taken as given, as it was assumed above, by setting $\bar{g}=g$. The capital accumulation equation furthermore implies that $i / k=\delta$. Steady state investment therefore satisfies $i=\delta(k / h) h$. The steady state ratio of investment over GDP is thus

$$
i / y=\delta(k / h)(h / y)=\delta(k / h)^{1-\alpha}=\delta\left[\alpha(1-\alpha)^{-1} w\left(r^{k}+\delta\right)^{-1}\right]^{1-\alpha}=\delta \alpha m\left(r^{k}+\delta\right)^{-1} .
$$

Solving the last equation for $\delta$ yields

$$
\delta=r^{k}(i / y)(\alpha m-i / y)^{-1}
$$


Hence, $\delta$ can be calibrated such that $i / y$ can be taken as given, as it was assumed above. The steady state capital stock then follows from the capital accumulation equation: $k=i / \delta$. Given $k$, we obtain the steady state level of claims on non-financial firms by financial intermediaries from the market clearing condition: $s^{k}=k$. On the fiscal side, we take the steady state ratio of government debt over GDP $b / y$ as given by calibrating the steady state level of taxes $\bar{\tau}$, such that

$$
b=(b / y) y, \quad \bar{\tau}=g+r^{b} b .
$$

To equalize the demand for government bonds by financial intermediaries $s^{b}$ and bond supply by the government $b$, given $s^{k}$, we calibrate $\bar{\omega}$ accordingly, as $\omega=\bar{\omega}$ and $s^{b} /(1-\omega)=\phi n=$ $s^{k} / \omega$, or

$$
\omega=\left(s^{k} / s^{b}\right)\left(1+s^{k} / s^{b}\right)^{-1}
$$

Given $b$, we thus obtain the steady state level of the intermediaries' government bond holdings from the market clearing condition: $s^{b}=b$. The remaining financial variables then follow as

$$
n=s^{k}(\omega \phi)^{-1}, \quad p=\phi n, \quad d=p-n
$$

\section{B The Model without Financial Frictions}

This appendix describes the version of the model without financial frictions and financial intermediaries. In this model, there are no bankers and households are thus formed entirely by infinitely lived workers with mass unity. Households save by investing in government bonds and by purchasing claims issued by intermediate goods firms. Accordingly, the budget constraint of a representative household becomes

$$
c_{t}+s_{t}^{b}+q_{t} s_{t}^{k}+\tau_{t} \leq w_{t} h_{t}+\left(1+r_{t}^{b}\right) s_{t-1}^{b}+\left(1-\bar{\tau}^{k}\right)\left(1+r_{t}^{k}\right) q_{t-1} s_{t-1}^{k}+\Sigma_{t} .
$$

We have introduced a flat-rate tax on capital income $\bar{\tau}^{k}$ whose function is discussed below. With $\Lambda_{t, t+1}$ as in the main text, the first-order conditions for the household's choices of $s_{t}^{b}$ and $s_{t}^{k}$ are

$$
\begin{aligned}
& s_{t}^{b}: \quad 1=\beta E_{t} \Lambda_{t, t+1}\left(1+r_{t+1}^{b}\right), \\
& s_{t}^{k}: \quad 1=\beta E_{t} \Lambda_{t, t+1}\left(1-\bar{\tau}^{k}\right)\left(1+r_{t+1}^{k}\right) .
\end{aligned}
$$


As in the main text, the monetary authority sets the risk-free nominal interest rate $r_{t}^{n}$. A Fisher relation defines the ex-post gross real interest rate on government bonds:

$$
1+r_{t}^{b}=\left(1+r_{t-1}^{n}\right) \pi_{t}^{-1}
$$

On the fiscal side, the government budget constraint becomes

$$
b_{t}+\tau_{t}+\bar{\tau}^{k}\left(1+r_{t}^{k}\right) q_{t-1} s_{t-1}^{k}=g_{t}+\left(1+r_{t}^{b}\right) b_{t-1} .
$$

The rational expectations equilibrium of this model is then the set of sequences $\left\{c_{t}, h_{t}, w_{t}\right.$, $\left.i_{t}, k_{t}, q_{t}, y_{t}, m_{t}, \pi_{t}, \pi_{t}^{*}, \Xi_{1, t}, \Xi_{2, t}, \Delta_{t}, r_{t}^{k}, r_{t}^{b}, s_{t}^{k}, s_{t}^{b}, b_{t}\right\}_{t=0}^{\infty}$ and shadow prices $\left\{\lambda_{t}\right\}_{t=0}^{\infty}$, such that for given initial prices and initial values, a fiscal policy $\left\{g_{t}, \tau_{t}\right\}_{t=0}^{\infty}$, a monetary policy $\left\{r_{t}^{n}\right\}_{t=0}^{\infty}$, and sequences of shocks $\left\{a_{t}, \xi_{t}\right\}_{t=0}^{\infty}$, conditions (1)-(2), (10)-(14), (19)-(20), (23)-(26), (B.1)(B.4), and the transversality conditions are satisfied. The tax $\bar{\tau}^{k}$ is calibrated such that this model implies the same steady state values for the relevant variables as the model with financial intermediaries, to make the impulse responses shown in the main text comparable. In particular, as $r_{t}^{b}$ replaces the deposit rate $r_{t}^{d}$ in this model, without any adjustment there would be no steady spread between $r_{t}^{k}$ and $r_{t}^{b}$. This means that steady state capital, investment, output, etc. would be higher than in the model with financial intermediation. To address this issue, we take a steady state that satisfies $r^{k}=r^{b}+\Gamma$, with $\Gamma>0$ as in the main text and $r^{b}=r^{n}=\beta^{-1}-1$, and we calibrate $\bar{\tau}^{k}$ to generate this spread. In particular, (B.1)-(B.2) imply that

$$
1+r^{b}=\left(1-\bar{\tau}^{k}\right)\left(1+r^{k}\right)=\left(1-\bar{\tau}^{k}\right)\left(1+r^{b}+\Gamma\right)
$$

or

$$
\bar{\tau}^{k}=\Gamma\left(1+r^{b}+\Gamma\right)^{-1}>0
$$

For a small spread, $\bar{\tau}^{k}$ will be small enough not to have a significant impact on the dynamics. In addition, we need to change the calibration of $\bar{\tau}$ to have identical values for the fiscal variables:

$$
\bar{\tau}=g+r^{b} b-\bar{\tau}^{k}\left(1+r^{k}\right) s^{k} .
$$

The steady state calculations for the remaining relevant variables and parameters are identical to those described in Appendix A. 